Sharif University of Technology
Scientia Iranica
Transactions E: Industrial Engineering
hCIENTIA

\title{
Scheduling of periodic services to customers in dispersed locations from heterogeneous multi-agent companies considering uncertainty: A real case study
}

\author{
H. Jafar-Zanjani ${ }^{a}$, M. Zandieh ${ }^{\mathrm{b}, *}$, and M. Khalilzadeh ${ }^{\mathrm{a}}$ \\ a. Department of Industrial Engineering, Science and Research Branch, Islamic Azad University, Tehran, Iran. \\ b. Department of Industrial Management and Information Technology, Management and Accounting Faculty, Shahid Beheshti \\ University, G.C., Tehran, Iran.
}

Received 10 February 2019; received in revised form 19 August 2019; accepted 10 November 2019

\author{
KEYWORDS \\ Scheduling; \\ Bi-objective \\ optimization; \\ Robust possibilistic \\ programming; \\ Genetic algorithm; \\ Uncertainty; \\ Augmented epsilon \\ constraint.
}

\begin{abstract}
This study investigates the problem of scheduling periodic services from service providers to customers located in different places that need different services. The service centers are also located in different positions, each of which has a limited number of teams with the capability of performing one or some services. The goal is to simultaneously minimize 'total service costs' and 'total earliness/tardiness' in providing services for customers. Providing an optimal maintenance schedule is a significant challenge for those companies with dispersed supply centers. In this paper, a novel bi-objective mixed integer linear programming model along with augmented epsilon constraint method is presented to exactly solve this problem. Then, a bi-objective meta-heuristic technique based on genetic algorithm is proposed and its performance in solving large-scale problems is assessed. Companies may face uncertain parameters when using the robust possibilistic programming approach to diminish the risk of decision-making. Finally, the performance of the proposed model and solution approaches is evaluated in the context of a real case study in maintenance scheduling of Compressed Natural Gas (CNG) stations equipment in Iran.
\end{abstract}

(C) 2021 Sharif University of Technology. All rights reserved.

\section{Introduction}

To remain active and compete in the global business market, companies are experiencing a transformation from a centralized structure to a decentralized one. In other words, considering the geographical dispersion of customers, companies establish representatives or other

\footnotetext{
*. Corresponding author. Tel.: +98212243182;

Fax: +98212243183

E-mail addresses: hjz59@yahoo.com (H. Jafar-Zanjani);

m_zandieh@sbu.ac.ir (M. Zandieh); khalilzadeh@srbiau.ac.ir (M. Khalilzadeh)
}

doi: $10.24200 /$ sci. 2019.52736 .2864 similar agents in different places to provide customers with more suitable services at lower prices and a shorter waiting time. Such systems are called Multi-Factory Production (MFP) [1].

These product supply centers or public service centers, which consist of several machines and equipment, are dispersed in several places to ensure availability in a shorter span of time with a lower cost [2]. One of the main issues about dispersed service centers is the repair and maintenance planning of facilities and equipment to increase their reliability and availability and also provide customers with the required services or products at each time interval with less tardiness.

However, the failure of components in the produc- 
tion and service systems is an undeniable fact and it may be the result of inadequate testing and inspection, poor maintenance, human error, etc. Implementation of more efficient equipment can enhance system productivity and profitability, which depends intensively on the reliable maintenance strategies in a system $[3,4]$.

Generally, to improve the system reliability, implementing optimal service plans is important to managers if the equipment is active and requires specific periodic services (maintenance), while heterogeneous service centers can only provide limited services. Also, if these centers are managed in an integrated manner, providing a suitable schedule for the repair and maintenance of the existing facilities/equipment is a necessity [3].

With the advent of recent technology to manufacture good products with high quality and to design highly reliable and efficient systems, the importance of maintenance activities and maintenance management has considerably risen in all sectors of manufacturing companies and service organizations $[3,5]$.

Many researchers and practitioners have shown interest in contributing to the improvement of equipment availability level, cost-effectiveness, performance efficiency, on-time delivery, product quality, environmental requirements, etc. [6-9]. In other words, maintenance strategy is employed to enhance the reliability and robustness of the equipment by reducing unplanned downtimes, eliminating unforeseen failures, and minimizing the maintenance costs that play a significant role in reaching reliability and safety requirements [10-12].

However, since the capacity of maintenance service centers is limited in each period, some services may not be available if these periodic services are not scheduled. Thus, optimal scheduling enhances the reliability of each facility and reduces the costs for the company.

Owing to the flexibility and dynamic variations of the target market, the classic centralized production planning and scheduling methods and their mechanisms are no longer responsive. This motivation may push companies to establish their facilities and service centers in dispersed places to satisfy the customers' needs. The above problem can be well fitted to unrelated parallel machines category, but it is so complicated due to the dispersed production and service centers.

In some instances, the scheduling problems are more complex than the above-mentioned conditions and occasionally, some customers with geographically dispersed locations demand a product or service which can be satisfied by different suppliers based on the product/service brand. Each of these suppliers has different service providers in different places. Therefore, the plan should identify the main supplier and the correspondent servicer and, finally, specify the job sequence for the selected servicer. Accordingly, the Multi-Factory Production (MFP) scheduling problems are NP-hard, implying that finding their solutions without explicit enumeration methods is impossible and their computational time exponentially increases as the size of the problem raises. Moreover, determining the optimum solution using Mixed Integer Linear Programming (MILP) model is not efficient, especially in large-scale instances [13].

MILP model can merely solve small-scale problems associated with MFP scheduling, while metaheuristic techniques are usually employed to handle large-scale ones. Here, heuristic methods can only solve the problem of parallel machines on a small scale and they may not be the best option in terms of capability/efficiency as the problem size increases and gets closer to the real size [14].

As a real case study of an MFP system, one can consider Compressed Natural Gas (CNG) stations that are controlled by a supervisor, where there is a centralized supervision and management who controls the activities of all stations. Repair times are defined by maintenance experts based on Preventive Maintenance (PM) models and, then, central management should implement the repair plan with the lowest cost and earliness/tardiness using the existing heterogeneous companies.

The scheduling of periodic maintenance services of heterogeneous multi-agent companies with a limited capacity for customers in dispersed locations can be considered an important problem of the MFP system. In some of the conducted research on MFP, a simple form of this problem has been studied; for example, consider the following simple problems: delivery of only a single product to a customer or a set of customers, only one time period, heterogeneity of factories, and other simple assumptions that neglect real-world conditions. However, the proposed model and the solution approach in this study mostly stand on real assumptions.

The first contribution of this paper is development of a novel bi-objective optimization model in which real assumptions including heterogeneous manufacturers with limited capacity, multi-period service scheduling, soft time window in providing services, and geographically dispersed locations of factories and customers are considered in the MFP system. The second contribution is the introduction of both exact and metaheuristics methods for solving small-scale and largescale problems, respectively. The third contribution is the tackling of parameter uncertainty using Robust Possibilistic Programming (RPP). Moreover, this study includes a case study of Iranian CNG stations with periodic maintenance service scheduling as a real problem. 
In summary, the main purpose of this research is to provide a bi-objective model and a solution approach to solve maintenance scheduling and planning in the heterogeneous MFP system. This model minimizes the total tardiness/earliness in the execution of maintenance under uncertainty. This research is organized into six sections. In Section 2, the literature is reviewed. In Section 3, the problem is described. In Section 4, the proposed bi-objective optimization model, robust programming approach to dealing with uncertainty, and the exact and meta-heuristics solution approaches are elaborated. In Section 5, the case study and numerical analysis result are presented. Section 6 concludes the paper by discussing the results and suggesting some directions for future research.

\section{The literature review}

A large variety of techniques have been developed for Parallel Machine Scheduling (PMS). For example, Balakrishnan et al. [15] studied unrelated PMS using MILP model. They could successfully plan a two-PMS problem with up to 10 jobs. In this respect, Zhu and Heady [16] modeled an MILP for unrelated PMS.

An exact solution based on Branch and Bound (B\&B) technique was used to solve unrelated PMS problems with 30 jobs [17]. Furthermore, other researchers, including Ruiz et al. [18], proposed some heuristic methods to solve PMS problems on a smaller scale and, then, evaluated their methods using the above-mentioned exact techniques.

Kanyalkar and Adil [19] categorized MFP as unrelated PMS problems. They introduced MFP including its differences against single (centralized) factory production. Products are produced in multiple factories in MFP and the corresponding manufacturers may be deployed in dispersed locations. Therefore, some of these factories may be close to customers, while others may not. Nevertheless, all factories are not capable to accomplish all jobs. In other words, there is a term called "capability of factory" and the capacity of every factories varies.

Behnamian and Ghomi [1] considered an MFP model in which each factory has some parallel machines with different speeds, each. Thus, job processing time could vary in each factory. The goal was to minimize the completion time or makespan. This problem could be investigated in unrelated PMS category; however, it was assumed that the machines in the same group were identical, while each group had different machines from other groups. They also presented a GA for solving large-scale instances, in addition to the design of a computational model for this problem.

A complicated study was performed on multifactory scheduling with limited service using a real case study in Jersey production factory in Belgium [20].
The objective was defined as the minimization of the weighted combination of delay and earliness. The due dates and change times are sequence dependent. Their research was developed considering the geographical dispersion of manufacturing sites.

A review of the multi-factory machine scheduling for the first time was provided by Behnamian and Fatemi Ghomi [21]. This paper classified and reviewed the literature in terms of shop environments including single machine, parallel machines, flow shop, job shop, and open shop.

An Unrelated Parallel Machine Scheduling (UPMS) problem was considered with time-dependent deterioration and multiple rate-modifying activities in [22]. In the proposed UPMS problem, they simultaneously determined the schedule of the jobs as well as the number and positions of rate-modifying activities to minimize the makespan. In this paper, extensive computational experiments were also conducted through randomly generated examples to evaluate the performance of the proposed algorithms.

Mensendiek et al. [23] addressed the problem of minimizing the total tardiness of a set of jobs to be scheduled on identical parallel machines, where jobs could only be delivered on certain fixed delivery dates. The authors developed and empirically evaluated both optimal and heuristic solution procedures to solve their problem. The results proved that both approaches provided optimal solutions to instances with less than 20 jobs and different tightness of delivery dates in a reasonable computational time.

Poursabzi et al. [24] studied the problem of capacitated lot-sizing and scheduling in job shops with a carryover setup and a general product structure. They first developed an efficient MILP model for the problem and then, they adapted an available Lower Bound (LB) in the literature to their problem. Some heuristic methods based on the production shifting concept were also proposed to solve this problem.

The scheduling problem in a Hybrid Flow Shop (HFS) with unrelated parallel machines was investigated in [25]. In this paper, a Lagrangian Relaxation (LR) algorithm was developed to handle the HFS scheduling problem and two approaches, namely simplification of sub-problems and dominance rules, were designed to solve the sub-problems generated in each iteration.

Furthermore, over the last few decades, numerous papers with various methods have been published on maintenance modeling and optimization [11,12,26-32]. For example, Garg et al. [27] presented the periodic $\mathrm{PM}$ of a system with deteriorated components, in which PM simultaneously considered three actions of mechanical service, repair, and replacement for a multicomponents system based on the maintenance cost. In this paper, the degraded behavior of the component 
was modeled in the reliability equation, and the effect of PM actions on reliability was formulated based on the maintenance-benefit analysis. They also presented a two-phase approach to the statistical analysis of failure data of a crank-case manufacturing in a twowheeler industry, covering a period of one year. In this paper, to determine the global values for the probability distribution of failure and repair, the particle swarm optimization was developed [28].

Niwas and Garg [3] presented an approach to analyzing the behavior of an industrial system under costfree warranty policy. The distribution of failure and repair time was assumed to be negative exponential, and various parameters such as reliability, mean time to system failure, availability, and expected profit were derived for a system using a mathematical modeling with Markov process. In another work, a greedy heuristic-based local search algorithm was developed to provide a system maintenance schedule for multicomponent systems by coordinating the recommended component maintenance times to reduce system downtime costs. The minimization of the sum of downtime as well as earliness and tardiness costs of scheduling was defined as the objective of the proposed iterative algorithm [29].

Usually, research works on scheduling use population-based meta-heuristics more frequently to solve these types of problems. Among them, GAs usually outperform other population-based and local search algorithms [33]. For example, GA was developed for the optimization of the maintenance scheduling of generating units in a power system in [34]. An efficient GA was employed to solve the resource-constrained project scheduling problem in [35]. An extended GA was proposed for solving the open-shop scheduling problem in [36]. A hybrid GA approach was presented for preventive remanufacturing planning of production equipment under operational and imperfect maintenance constraints in [36]. In addition, GA is still of great interest to researchers for not only scheduling but also nonlinear constrained optimization problems [37].

Maintenance optimization is a multi-objective problem in nature and it usually needs to achieve a trade-off between time and reliability objectives. The multi-objective meta-heuristic methods based on GA, e.g., Non-dominated Sorting Genetic Algorithm II (NSGA-II), are applied for solving bi-objective scheduling problems. Recently, NSGA-II has been used to solve the imperfect PM optimization [38]. It handles the multi-objective optimization of PMS integrated with multi-resources PM planning [38]. Moreover, it was employed for energy-efficient job shop scheduling [39]. Regarding the efficient performance of GA and NSGA-II, we will use this approach to solve the largescale scheduling problem to be described in detail in the next sections.

\section{Problem definition}

In this paper, scheduling of periodic services to customers in dispersed locations is studied in which customers receive different services in each period. The service centers are also positioned in dispersed locations each of which has a limited number of teams capable to offer one or some services. The duration time and cost of services are also considered heterogeneous.

Suppose a network including two levels/echelons. On one level, there are service centers with a limited number of teams and facilities, while the customers are the applicants for services on another level. Both levels are geographically dispersed in vast regions. The customers are placed in different places and there are one or several teams in each center capable of providing one or some services with different time durations and costs. The goal is to simultaneously minimize 'total service costs' and 'total earliness/tardiness' in providing services for customers through optimum assignment of required customers' services to service centers and scheduling of offering services.

Service offering is periodically carried out. The required services by each customer are determined in each period and a soft time window is taken into account to fulfill such a need. Considering the offered services as "jobs", existing teams in each factory as "machines", and time needed to provide each service as "processing time of machine, this problem can be stated as an UPMS problem to present services from multiple factories to multiple customers. The goal is to seek optimal scheduling to provide services in each period to customers by existing teams in each factory, where tardiness/earliness and total costs are minimized. In this paper, the UPMS problem with Multiple Factories/servers and Clients called UPMS_MFC is investigated. Table 1 shows the characteristics of this problem based on the notation in the literature.

The other assumptions in this study used in modeling and solving the problem are as follows:

- It is possible to perform a service before or after its due date up to a certain limit determined as upper or LBs;

- No pre-emption of services is allowed, i.e., services should be completely delivered/presented after initiation;

- Number of factories/service centers and service teams is finite;

- Number of client centers and their required services is limited;

- The planning horizon comprises a finite number of time periods with given and fixed lengths;

- A given service/job may be ordered by a customer in several periods; 
Table 1. The characteristics of studied Unrelated Parallel Machine Scheduling with Multiple Factories/servers and Client (UPMS_MFC) problem in this research.

\begin{tabular}{|c|c|c|}
\hline Factor & Abbreviation symbol & Explanations \\
\hline $\begin{array}{l}\text { Machines } \\
\text { (servicer } \\
\text { teams) } \\
\{\alpha\} \\
\end{array}$ & UR: Unrelated machines & $\begin{array}{l}\text { Each factory or service center has multiple machines/ } \\
\text { teams with different speeds and costs, which can be processed in parallel. }\end{array}$ \\
\hline \multirow{7}{*}{ 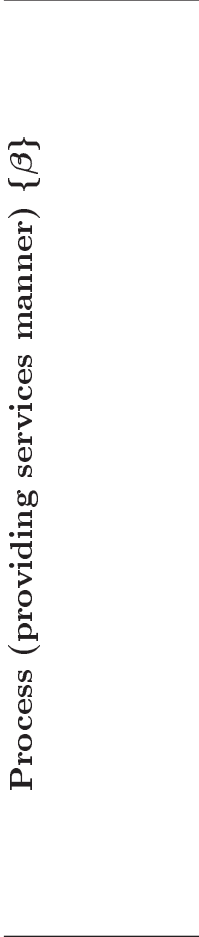 } & DD: Due Date & A due date is considered for ordered services. \\
\hline & RD: Release Date & $\begin{array}{l}\text { Start time of each job/service depends on its availability. } \\
\text { In other words, all jobs cannot be presented at the outset of } \\
\text { planning horizon. It is also possible that all ordered } \\
\text { services in each period cannot be presented at the outset of } \\
\text { that period. }\end{array}$ \\
\hline & $\begin{array}{l}\text { SD: Sequence Dependent } \\
\text { setup time }\end{array}$ & $\begin{array}{l}\text { The setup time of each machine/team depends on the } \\
\text { jobs sequence. This time significantly depends on } \\
\text { distance between different client centers and } \\
\text { their correspondent service centers. }\end{array}$ \\
\hline & ER: Eligibility Restriction & $\begin{array}{l}\text { Each factory's teams cannot offer all services. In other } \\
\text { words, there is a limitation on proficiency of } \\
\text { machines/teams. }\end{array}$ \\
\hline & N_PC: No Precedence Constraints & $\begin{array}{l}\text { There is no precedence or posterior in providing services, } \\
\text { i.e., no service is predecessor or successor of } \\
\text { another one (no job should be done before or } \\
\text { after that job). }\end{array}$ \\
\hline & N_B: No Breakdown & $\begin{array}{l}\text { All machines/service teams are permanently available, i.e., } \\
\text { no breakdown is allowed. }\end{array}$ \\
\hline & N_BP: No Batch Processing & $\begin{array}{l}\text { Each machine/team can only perform one process or } \\
\text { service at the time, i.e., there is no way to do some services by a team. }\end{array}$ \\
\hline \multirow[t]{2}{*}{ 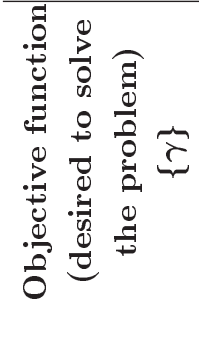 } & SC: Service Cost & $\begin{array}{l}\text { Total service costs including operational costs of service } \\
\text { by each team for each service in each service center, } \\
\text { transportation cost of teams for carrying } \\
\text { them from service centers to clients' cites, } \\
\text { and fixed cost of tardiness/earliness in providing } \\
\text { services should be minimized. }\end{array}$ \\
\hline & ET: Earliness and Tardiness & Total weighted of tardiness and earliness in providing services \\
\hline
\end{tabular}

- All services should be performed according to the planning horizon; however, some services belonging to a given period may be presented in the succeeding or preceding periods;

- Each team returns to its factory upon accomplishing the service in each period and then, getting prepared to do the next service and meeting the customer;

- The duration time of each service accomplished by each team is uncertain.

\section{Modeling and solution approach}

In this section, the solution approach is described. First, a bi-objective mixed linear programming model along with an Augmented Epsilon Constraint (AEC) is given to exactly solve the studied problem. Then, a bi-objective meta-heuristic algorithm based on GA is proposed and its performance is assessed to see whether one can apply it to solve large-scale instances or not. Uncertainty of some parameters such as service time is handled and controlled through RPP.

\subsection{Bi-objective optimization model Sets and indices}

Index for factories/service centers:

$$
F=\{1,2, \ldots, f, \ldots,|F|\}
$$

Index for customers/client centers:

$$
K=\{1,2, \ldots, k, \ldots,|K|\}
$$


Index for jobs/services:

$$
J=\{1,2, \ldots, j, \ldots,|J|=n\}
$$

Index for teams/machines in factory $f$ :

$$
S_{f}=\left\{1,2, \ldots, i, \ldots,\left|S_{f}\right|=m_{f}\right\}
$$

Index for time periods/days (e.g., months of a year):

$$
H=\{1,2, \ldots, t, \ldots,|H|\}
$$

\section{Parameters/input data}

$d_{t j k} \quad 1$ if time period $t$ is predetermined due date to do service $j$ for customer $k ; 0$ otherwise

$\xi_{j} \quad$ Maximum deviation from due date of service $j$ (based on time period). The deadline $\left[\left(t-\xi_{j}\right) \cdot d_{t j k},\left(t+\xi_{j}\right) \cdot d_{t j k}\right]$ is considered for providing services

\section{$r_{j k t} \quad$ Availability time of service $j$ for} customer $k$ in period $t$

$\tilde{p}_{\text {jif }} \quad$ Duration time of service $j$ accomplished by team $i$ belonging to factory $f$ (uncertain parameter)

$w_{j} \quad$ Weight or importance of service $j$

$\nu_{j k i f} \quad$ Operational cost of providing service $j$ for customer $k$ by team $i$ in factory $f$

$f_{j k} \quad$ Fixed cost of earliness/tardiness in presenting service $i$ to customer $k$

$t c_{f k} \quad$ Transportation cost (round trip) of each team from factory $f$ to customer $k$

$t_{f k} \quad$ Transportation time of each team from factory $f$ to customer $k$

$S_{i f j k j^{\prime} k^{\prime}} \quad$ Setup time of team $i$ belonging to factory $f$ to provide service $j^{\prime}$ for customer $k^{\prime}$ after presenting service $j$ of customer $k$

$\omega \quad$ Tardiness weight in offering services

$T \quad$ Duration time of each period (e.g., each period is 1 month/30 days)

$M \quad$ A large positive arbitrary number

\section{Decision variables/outputs}

$x_{j t k t^{\prime} i f} \quad 1$ if service $j$ for customer $k$ in period $t$ is offered by team $i$ belonging to factory $k$; 0 otherwise

$y_{t^{\prime \prime} j t k j^{\prime} t^{\prime} k^{\prime} i f} 1$ if in period $t^{\prime \prime}$, service $j$ for customer $k$ in period $t$ is offered before service $j^{\prime}$ for customer $k^{\prime}$ in period $t^{\prime}$ by team $i$ belonging to factory $k$; 0 otherwise in period $t$ is fulfilled with tardiness; 0 otherwise
$c_{j t k t^{\prime}}$
Duration time of service $j$ belonging to customer $k$ in period $t$ which is done in period $t^{\prime}$
$T_{j t k}$
$E_{j t k}$
Tardiness in fulfilling service $j$ belonging to customer $k$ in period $t$
Earliness in fulfilling service $j$ belonging to customer $k$ in period $t$

$$
\begin{gathered}
\text { Minimize } S C=\sum_{j} \sum_{t} \sum_{k} \sum_{t^{\prime}} \sum_{i} \sum_{f}\left(v_{j k i f}+t c_{f k}\right) \\
x_{j t k t^{\prime} i f}+\sum_{t} \sum_{j} \sum_{k} f_{j k} z_{j t k},
\end{gathered}
$$

$$
\text { Minimize } E T=\sum_{j} \sum_{k} \sum_{t} w_{j}\left(\omega T_{j t k}+(1-\omega) E_{j t k}\right) \text {. }
$$

Eq. (1) minimizes total service costs including operational costs of service, transportation cost of teams from service centers to clients' cites, and fixed cost of tardiness/earliness in providing services. In Eq. (2), total weighted tardiness and earliness in presenting services are minimized. In Eq. (2), $\omega$ and $(1-\omega)$ are important factors associated with having no tardiness or earliness, respectively. If both tardiness and earliness are equally important, the parameter $\omega$ is considered as $\omega \cong 0.5$; however, if earliness has no effect on providing services, this parameter is considered as $\omega \cong 1$.

The constraints of the studied problem are as follows:

$\sum_{t^{\prime}} \sum_{i} \sum_{f} x_{j t k t^{\prime} i f}=d_{t j k} ; \quad \forall j \in J, t \in T, k \in K$,

$\sum_{t} \sum_{i} \sum_{f} x_{j t k t^{\prime} i f} \leq 1 ; \quad \forall j \in J, t^{\prime} \in T, k \in K$,

$\sum_{t} \sum_{j} \sum_{i} \sum_{f} x_{j t k t^{\prime} i f} \leq 3 ; \quad \forall t^{\prime} \in T, k \in K$

$\sum_{t} \sum_{j} \sum_{k} x_{j t k t^{\prime} i f} \leq 2 ; \quad \forall i \in S_{f}, f \in F, t^{\prime} \in T$

$x_{j t k t^{\prime \prime} \text { if }} \leq \sum_{j^{\prime}} \sum_{t^{\prime}} \sum_{k^{\prime}} y_{t^{\prime \prime} j^{\prime} t^{\prime} k^{\prime} j t k i f}$

$\forall j \in J, t, t^{\prime \prime} \in T, k \in K, i \in S_{f}, f \in F$,

$\sum_{j} \sum_{k} y_{t^{\prime \prime} j t k j t k i f} \leq 1 ; \quad t, t^{\prime \prime}, \in T, i \in S_{f}, f \in F$,

$y_{t^{\prime \prime} j t k j^{\prime} t^{\prime} k^{\prime} i f}+y_{t^{\prime \prime} j^{\prime} t^{\prime} k^{\prime} j t k i f} \leq 1$;

$t, t^{\prime}, t^{\prime \prime} \in T, i \in S_{f}, f \in F, j, j^{\prime} \in J, k, k^{\prime} \in K$,

$y_{t^{\prime \prime \prime} j t k j^{\prime \prime} t^{\prime \prime} k^{\prime \prime} i f} \geq y_{t^{\prime \prime \prime} j t k j^{\prime} t^{\prime} k^{\prime} i f}+y_{t^{\prime \prime \prime} j^{\prime} t^{\prime} k^{\prime} j^{\prime \prime} t^{\prime \prime} k^{\prime \prime} i f}-1$; 


$$
\begin{aligned}
& t, t^{\prime}, t^{\prime \prime}, t^{\prime \prime \prime} \in T, i \in S_{f}, f \in F, j, j^{\prime}, j^{\prime \prime} \\
& \in J, k, k^{\prime}, k^{\prime \prime} \in K, \\
& c_{j t k t^{\prime \prime}} \geq c_{j^{\prime} t^{\prime} k^{\prime} t^{\prime \prime}}+S_{i f j^{\prime} k^{\prime} j k}+\tilde{p}_{j i f} \\
& +\left(y_{t^{\prime \prime} j^{\prime} t^{\prime} k^{\prime} j t k i f}-2\right) M ; \quad \forall t, t^{\prime}, t^{\prime \prime} \in T, k, \\
& k^{\prime} \in K, j, j^{\prime} \in J, \quad i \in S_{f}, f \in F ; \\
& \quad(j, t, k) \neq\left(j^{\prime}, t^{\prime}, k^{\prime}\right), \\
& c_{j t k t^{\prime}} \geq r_{j k t^{\prime}}+t_{f k}+\tilde{p}_{j i f}+\left(x_{j t k t^{\prime} i f}-1\right) M ; \\
& \forall j \in J, t, t^{\prime} \in T, k \in K, i \in S_{f}, f \in F, \\
& z_{j t k}=d_{t j k} \sum_{t^{\prime} \neq t} \sum_{i} \sum_{f} x_{j t k t^{\prime} i f} ;
\end{aligned}
$$

$\forall j \in J, t \in T, k \in K$.

Eq. (14) is shown in Box I.

$$
\begin{aligned}
& l_{j t k} \geq \sum_{t^{\prime}>t} \sum_{i} \sum_{f} x_{j t k t^{\prime} i f} ; \quad \forall j \in J, t \in T, k \in K, \\
& l_{j t k} \leq 1-\sum_{t^{\prime} \leq t} \sum_{i} \sum_{f} x_{j t k t^{\prime} i f} ; \quad \forall j \in J, t \in T, k \in K \\
& T_{j t k} \geq d_{t j k}\left[\left(\sum_{t^{\prime} \neq t} \sum_{i} \sum_{f} t^{\prime} \cdot x_{j t k t^{\prime} i f}-t-1\right)\right. \\
& \left.\quad+\sum_{t^{\prime}} \frac{c_{j t k t^{\prime}}}{\tau}\right]+\left(l_{j t k}-1\right) M
\end{aligned}
$$

$\forall j \in J, t \in T, k \in K$

$$
\begin{aligned}
E_{j t k} & \geq d_{t j k}\left[\left(t-\sum_{t^{\prime} \neq t} \sum_{i} \sum_{f} t^{\prime} \cdot x_{j t k t^{\prime} i f}\right)\right. \\
& \left.-\sum_{t^{\prime}} \frac{c_{j t k t^{\prime}}}{\tau}\right]-\left(l_{j t k}+\left(1-z_{j t k}\right)\right) M ;
\end{aligned}
$$

$\forall j \in J, t \in T, k \in K$,

$$
T_{j t k} \leq \xi_{j}+M\left(1-d_{t j k}\right) ; \quad \forall j \in J, t \in T, k \in K,
$$

$$
\begin{aligned}
& E_{j t k} \leq \xi_{j}+M\left(1-d_{t j k}\right) ; \quad \forall j \in J, t \in T, k \in K, \\
& c_{j t k t^{\prime}} \leq \tau ; \quad \forall j \in J, t, t^{\prime} \in T, k \in K, \\
& \left\{\begin{array}{l}
x_{j t k t^{\prime} i f}, y_{t j k j^{\prime} k^{\prime} i f}, z_{j t k}, l_{j t k} \in\{0,1\} \\
c_{j t k t^{\prime}}, T_{j t k}, E_{j t k} \geq 0
\end{array}\right.
\end{aligned}
$$

Eq. (3) ensures that each required service be offered for each customer in each period. Constraint (4) ensures that each customer can only request a given service at most once in each period. Constraint (5) controls the maximum number of services belonging to each customer in each period, e.g., each customer can use three different services in each period.

Constraint (6) shows the maximum number of services for each team, e.g., each team of every factory can present at most two different services. Constraint (7) shows that if any team provides services for a customer, it can be implied that this is either the first provided service by that team $\left(y_{t^{\prime \prime} j t k j t k i f}=1\right)$, or this team has already provided another service $\left(y_{t^{\prime \prime} j t k j^{\prime} t^{\prime} k^{\prime} i f}=0\right)$.

It is obvious that the first service offered by each team (if any) in each period is unique. This constraint is satisfied through Constraints (8) and (9), showing the precedence of two consecutive different services. It should be mentioned that no team can provide two different services simultaneously. It is also obvious that the sequence of providing services by each team in each period has transitive property, as shown in Constraint (10).

In Constraint (11), the duration time of a service is calculated only if another service is already presented. According to this constraint, if a given team is willing to do a specific service $\left(x_{j t k t^{\prime \prime} \text { if }}=1\right)$ while another service is already done by that team $\left(y_{t^{\prime \prime} j^{\prime} t^{\prime} k^{\prime} j t k i f}=1\right)$, the completion time of the second service equals that of the first service plus setup time for the second service (which equals the total needed time of returning the team from the first customer to factory plus needed time to transport the team to the second customer, i.e., $S_{i f j^{\prime} k^{\prime} j k}=t_{k^{\prime} f}+t_{f k}$ ) as well as processing time of the second service. It should be mentioned that this constraint will be dummy if any of the mentioned prerequisites is not active

$$
\left\{\begin{array}{c}
T_{j t k}=d_{t j k}\left[\left(\sum_{t^{\prime} \neq t} \sum_{i} \sum_{f} t^{\prime} \cdot x_{j t k t^{\prime} i f}-t-1\right)+\frac{c_{j t k t^{\prime}}}{\tau}\right] ; \sum_{t^{\prime} \neq t} \sum_{i} \sum_{f} t^{\prime} \cdot x_{j t k t^{\prime} i f}-t>0 \\
E_{j t k}=d_{t j k}\left[\left(t-\sum_{t^{\prime} \neq t} \sum_{i} \sum_{f} t^{\prime} \cdot x_{j t k t^{\prime} i f}\right)-\frac{c_{j t k t^{\prime}}}{\tau}\right] ; \sum_{t^{\prime} \neq t} \sum_{i} \sum_{f} t^{\prime} \cdot x_{j t k t^{\prime} i f}-t<0
\end{array}\right\}
$$

$\forall j \in J, t \in T, k \in K$ 
$\left(x_{j t k t^{\prime \prime}{ }_{i f}} \cdot y_{t^{\prime \prime} j^{\prime} t^{\prime} k^{\prime} j t k i f}=0\right)$ and Constraint (12) will be active which calculates the duration time of each team's first service.

Constraint (13) determines which services are subject to either tardiness or earliness. If a given service belongs to period $t\left(d_{t j k}=1\right)$ and is presented in any other period except period $t\left(\sum_{t^{\prime} \neq t} \sum_{i} \sum_{f} x_{j t k t^{\prime} i f}=\right.$ 1 ), it can be concluded that this service is done with time deviation from its due date. It should also be mentioned that if period $t$ has not already been assigned to a given service $\left(d_{t j k}=0\right)$, this equation will be dummy and consequently $z_{j t k}=0$.

Eq. (14) calculates tardiness and earliness in providing required services for each customer. This constraint can be linearized using Constraints (15) and (16). To do so, the auxiliary binary variable $l_{j t k}$ should be first defined as follows: 1 if a given service is presented with tardiness $\left(\sum_{t^{\prime} \neq t} \sum_{i} \sum_{f} t^{\prime} \cdot x_{j t k t^{\prime} i f}-t>0\right), 0$ otherwise. Then, using this variable and $z_{j t k}$ which was already explained, it is obvious that either tardiness or earliness would be added to the second objective function, or none of them.

Constraints (17)-(20) limit the maximum allowable tardiness and earliness in providing services to an upper bound. Constraint (21) controls the service time duration in each period. Finally, Constraint (22) shows decision variables and their domain including some binary variables and some nonnegative ones.

\subsubsection{Uncertainty control using RPP approach}

Usually, there is no complete certainty regarding most parameters in real optimization problems, while some of them are subject to obvious uncertainty. The problem solution may be inefficient if these uncertainties are not controlled. In the studied UPMS_MFC in this paper, the processing time of each job by each machine (duration time of presented service by each team, i.e., $\left.\tilde{p}_{j i f}\right)$ is considered uncertain. In this regard, mathematical programming techniques are applied in the following to handle such uncertainty, given that this uncertain parameter can be stated in terms of a fuzzy number.

Suppose that $T$ is a passive parameter. Although one cannot exactly determine its value, it is possible to limit it to a given interval of numbers according to previous knowledge, experience, and expert estimation, and this value with different probabilities is equal to any of existing numbers at this interval. For example, consider four numbers $\left(t_{1}<t_{2} \leq t_{3}<t_{4}\right)$, where $T$ cannot take a value lower than $t_{1}$ or more than $t_{4}$ (such a probability is negligible). Also, the highest probability belongs to values between $t_{2}$ and $t_{3}$. The probability of being equal to any number between $t_{1}$ and $t_{2}$ is linearly increasing, while the probability of being equal to any number between $t_{3}$ and $t_{4}$ is linearly decreasing. Based on the above, $\tilde{T}$ is limited to a trapezoid set called Trapezoidal Fuzzy Number (TFN) depicted in Figure 1. To handle the uncertain parameter $\left(\tilde{p}_{j i f}\right)$ in the studied UPMS_MFS, the following can be assumed according to the experts' opinions and historical data.

If some parameters are TFN in an optimization problem, one can employ different approaches such as possibilistic programming to solve the problem $[40,41]$ as a subset of fuzzy mathematical programming/optimization [42]. In the following, possibilistic programming is first described and, then, its newfangled expression integrated with robustness concept is presented. Finally, the robust version of UPMS_MFC is employed in this research.

Consider the following fuzzy programming model:

$$
\left\{\begin{array}{l}
\text { Min } c x \\
\text { s.t. } \\
A x \geq \tilde{\tilde{b}} \\
x \in X
\end{array}\right.
$$

where $\tilde{b}=\left(b^{1}, b^{2}, b^{3}, b^{4}\right)$ is a TFN vector and $b^{1}<$ $b^{2} \leq b^{3}<b^{4}$ are vectors of crisp numbers. According to possibilistic programming, a level $(\alpha \times 100) \%$ is first taken into account for constraints and then, a possibility measure alpha for constraints is considered as follows:

$$
\left\{\begin{array}{l}
\text { Min } \operatorname{cx} \\
\text { s.t. } \\
\operatorname{Poss}(A x \geq \tilde{b}) \geq \alpha \\
x \in X
\end{array}\right.
$$

According to the possibility measure, the abovementioned possibilistic programming equals the following defuzzified model $[40,41]$ :

$$
\left\{\begin{array}{l}
\text { Min } c x \\
\text { s.t. } \\
A x \geq \alpha \cdot \mathrm{b}^{4}+(1-\alpha) \mathrm{b}^{3} \\
x \in X
\end{array}\right.
$$

To improve the performance of the latter model in a research study conducted by Pishvaee et al. [43]

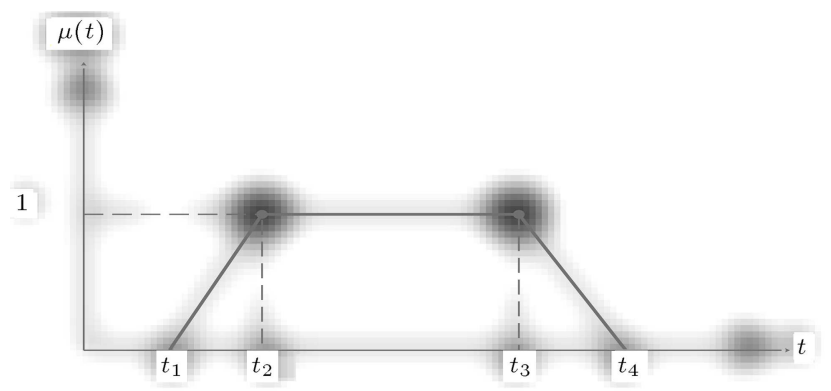

Figure 1. A trapezoidal fuzzy number. 
considering two concepts, i.e., feasibility robustness and optimality robustness, RPP was developed, in which possibility measure $\alpha$ was interactively determined according to robustness concept in the problem solution process. The general form of RPP is as follows:

$$
\left\{\begin{array}{l}
\text { Min } \quad c x+\varphi\left[\mathrm{b}^{4}-\left(\alpha \cdot \mathrm{b}^{4}+(1-\alpha) \mathrm{b}^{3}\right)\right] \\
\text { s.t. } \\
\text { Ax } \geq \alpha \cdot \mathrm{b}^{4}+(1-\alpha) \mathrm{b}^{3} \\
x \in X \\
0.5 \leq \alpha \leq 1
\end{array}\right.
$$

where $\varphi \geq 0$ is a control parameter obtained from sensitivity analysis. Also, $\alpha$ is a variable signifying to what extent the constraints can be applied. It is obvious that if $\varphi \rightarrow 0$, then $\alpha \rightarrow 0.5$ and if $\varphi \rightarrow \infty, \alpha \rightarrow 1$. According to the above-mentioned explanations, in RPP approach to solving to defined UPMS_MFC problem in this study, the parameter $\tilde{P}_{j i f}=\left(P_{j i f}^{1}, P_{j i f}^{2}, P_{j i f}^{3}, P_{j i f}^{4}\right)$ is first stated as a TFN and, then, Constraint (27) is replaced with Constraints (11) and (12).

$$
\begin{gathered}
c_{j t k t^{\prime}}-\left(r_{j k t^{\prime}}+\sum_{j^{\prime}} \sum_{k^{\prime}} S_{i f j^{\prime} k^{\prime} j k} y_{t j^{\prime} k^{\prime} j k i f}\right) \\
\geq\left(\alpha \cdot P_{j i f}^{4}+(1-\alpha) P_{j i f}^{3}\right) x_{j t k t^{\prime} i f}
\end{gathered}
$$

$\forall j \in J, t, t^{\prime} \in T, k \in K, i \in S_{f}, f \in F$.

Now, for calculating the objective functions, Constraints (28) and (29) should be rewritten in the same way as follows:

$$
\begin{aligned}
& \text { Minimize } S C=\sum_{j} \sum_{t} \sum_{k} \sum_{t^{\prime}} \sum_{i} \sum_{f}\left(v_{j k i f}+t c_{f k}\right) \\
& x_{j t k t^{\prime} i f}+\sum_{t} \sum_{i} \sum_{f} f_{j k} z_{j t k} \\
& +\varphi_{1} \sum_{j} \sum_{i} \sum_{f}\left[P_{j i f}^{4}-\left(\alpha \cdot P_{j i f}^{4}\right.\right. \\
& \left.\left.+(1-\alpha) P_{j i f}^{3}\right)\right],
\end{aligned}
$$

Minimize $E T=\sum_{t} \sum_{i} \sum_{f} w_{j}\left(\omega T_{j t k}+(1-\omega) E_{j t k}\right)$

$$
+\varphi_{2} \sum_{j} \sum_{i} \sum_{f}\left[P_{j i f}^{4}-\left(\alpha . P_{j i f}^{4}\right.\right.
$$$$
\left.\left.+(1-\alpha) P_{j i f}^{3}\right)\right]
$$

\subsection{Trade-off between objectives using AEC method}

As already pointed out, the objective of solving UPMS_MFC is to satisfy two objectives simultaneously: minimizing total costs of providing services for customers and minimizing total tardiness and earliness. In practice, there is a contradiction between objectives, namely by increasing the quality of one objective, the quality of another decreases, and vice versa. Accordingly, different approaches have been proposed to solve bi- or Multi-Objective Decision Making (MODM) problems such as Weighted Sum Method (WSM), Epsilon Constraint (EC), AEC, Goal Programming (GP), Lexicographic (Lex), etc. [44,45].

The general form of the MODM problem, Eq. (30), is given below:

$$
\left\{\begin{array}{l}
\operatorname{Min}\left(f_{1}(x), f_{2}(x), \ldots, f_{n}(x)\right) \\
x \in X
\end{array}\right.
$$

In EC method, one objective is first taken as the main objective, while the rest of objectives are limited to upper bound of epsilon $\left(e_{i}\right)$ and the following singleobjective model is obtained through Eq. (31):

$$
\left\{\begin{array}{l}
\operatorname{Minf}_{1}(x) \\
f_{i}(x) \leq e_{i} i=2,3, . ., n \\
x \in X
\end{array}\right.
$$

In EC method, by changing the values of $e_{i}$, different solutions are obtained which may not be efficient (weakly efficient). This difficulty has been resolved using AEC method by replacing the following model [46]:

$$
\left\{\begin{array}{l}
\operatorname{Minf}_{1}(x)-\sum_{i=2}^{n} \phi_{i} s_{i} \\
f_{i}(x)+s_{i}=e_{i} i=2,3, . ., n \\
x \in X \\
s_{i} \geq 0
\end{array}\right.
$$

where $s_{i}$ 's are nonnegative variables for shortage and $\phi_{i}$ is a parameter used for normalizing the value of the first objective function with respect to the $i$ th objective $\left(\phi_{i}=\frac{R\left(f_{1}\right)}{R\left(f_{i}\right)}\right)$. To better implement the AEC method, one can obtain the appropriate interval of epsilons $\left(e_{i} s\right)$ using Lex method [47].

In order to apply AEC method for solving the defined UPMS_MFC, the first objective function (minimizing total service costs, i.e., $f_{1}=\mathrm{SC}$ ) is considered as the main objective, while the second objective (minimizing total weighted tardiness and earliness, i.e., $f_{2}=\mathrm{ET}$ ), is limited to different values of epsilons and efficient solutions can be then obtained using Eq. (32) for different values of $e$. 


\subsection{Meta-heuristic solution approach}

As already mentioned, the complexity of PMS problems and the large size of real instances make the exact methods based on mathematical programming (such as the proposed MILP) inefficient. The exact mathematical models can only solve this type of problems in small sizes, while meta-heuristic algorithms are usually used to solve large-scale cases [48-51]. Given that the defined UPMS_MFC in this study is a much more complex version of PMS, besides the proposed mathematical model in the previous section, a bi-objective meta-heuristic method based on GA, i.e., non-dominated sorting genetic algorithm II, called NSGA-II, is employed to solve the large-scale instances efficiently.

The most important parts of NSGA-II involve determining the structure of the chromosomes (solution representation, neighborhood structure, crossover, and mutation) and fitness function. The structure of chromosomes should include at least all model variables as well as most of the problem constraints. Crossover and mutation operators should be easily applied to this structure. The structure of crossover and mutation should be defined such that the solution space can be completely explored with the capability of generating high-quality solutions. The main parts of NSGA-II are precisely explained in the following.

\subsubsection{Chromosome structure}

The designed chromosome for the studied problem in this research comprises two rows. The number of columns is equal to that of orders by customers from all services in all periods calculated based on parameter $d_{t j k}$. In other words, the number of columns in this matrix is equal to that of elements in the $d_{t j k}$ matrix. In the following, we are to determine which teams can meet the service order of each customer. Suppose that $t=3, j=3, k=2$, and $S=4$; therefore, a sample of this matrix is given as follows.

In Figure 2, a sample of chromosome structure designed for the studied problem in this paper is presented. In the first row, $d_{1.2 .2}$ signifies demand/order of customer 2 for service 2 in period 1 , and $d_{1.1 .1}$ indicates order of customer 1 for service 1 in period 1 . In the second row and first column, it can be observed that the order of customer 2 for service 2 in the first period is fulfilled by team \#2. It should be mentioned that for generating the chromosome's row, each order/demand is determined by those teams with the capability of providing that service. For instance, if teams \#1, \#2, and \#4 can satisfy the demand of $d_{1.2 .2}$, one of them is randomly selected and is placed in the second row of the chromosome.

Therefore, the first row represents the sequence that provides services for customers in each period, while the second row determines which team can fulfill each demand/order (specified in the first row). In other words, the presented chromosome structure shows both the sequence of providing services to customers and the assignment of demands/orders to teams.

\subsubsection{Fitness function}

After determining the chromosome structure, one should evaluate the objective function. According to Figure 2, it can be observed that the demands $d_{1.2 .2}, d_{1.2 .1}, d_{3.1 .2}$, and $d_{2.1 .1}$ are fulfilled by team \#2. According to the first row of the chromosome, the sequence for providing services to customers by team \#2 is determined. team \#2 visits customer 2 after exiting the factory first and provides service 2; then, they go to customer 1 to offer service 2 . Next, they go to customer 2 to present service 2 at first and subsequently service 1. According to this sequence, one can easily calculate the time when customers place a demand for services. Furthermore, the chromosome structure is designed in a way that any type of the requested service by any customer is provided by those teams with the capability of completing the task. This rule is applied to all teams. Finally, after determining the service time requested by each customer, one can calculate the tardiness or earliness in providing any demanded service by customers in each period. A penalty function is defined to limit the maximum possible amount of tardiness and earliness in presenting services. Suppose that there is a constraint below in Inequality (33):

$$
C_{i}(x) \leq C .
$$

The penalty function for these constraints is defined as follows:

$$
\text { Vio }=\max \left(\frac{C_{i}(x)}{C}-1.0\right) .
$$

Eq. (34) as a penalty function is calculated for the maximum amount of tardiness and earliness and is added to the main objective functions as Eqs. (35) and (36) in terms of multiplier:

$$
Z_{1}=F_{1}(x)+\alpha_{1} V i o
$$

\begin{tabular}{|c|c|c|c|c|c|c|c|c|c|c|}
\hline $\begin{array}{l}0 \\
\Xi \\
0 \\
o \\
0\end{array}$ & $d_{1.2 .2}$ & $d_{1.1 .1}$ & $d_{2.3 .2}$ & $d_{1.2 .1}$ & $d_{3.1 .2}$ & $d_{1.1 .2}$ & $d_{3.1 .1}$ & $d_{1.3 .2}$ & $d_{2.1 .2}$ & $d_{3.2 .2}$ \\
\hline$\Xi$ & 2 & 3 & 1 & 2 & 2 & 1 & 4 & 4 & 2 & 3 \\
\hline
\end{tabular}

Figure 2. A sample of chromosome structure. 


$$
Z_{2}=F_{2}(x)+\alpha_{2} V i o
$$

where $F_{1}(x)$ and $F_{2}(x)$ are the values of the first and second objective functions, and multipliers $\alpha_{1}$ and $\alpha_{2}$ determine the extent of penalty effect over each of the objective functions.

\subsubsection{Crossover}

The crossover operator increases the diversity/ dispersion of solutions and investigates the solution space extensively. In the proposed algorithm, a single-point crossover operator is used to generate the offspring. In this method, having chosen two parents to mate, a point is randomly selected in chromosome as the cut point. Then, the right parts of cut points are interchanged and, consequently, two new offspring are generated. Upon applying this method, the generated children exploit both of their parents' information/characteristics. Figure 3 depicts the applied crossover in this study (4 points are randomly chosen as cut points).

\subsubsection{Mutation}

As already pointed out, mutation operator avoids zeroing the probability of exploring each point of solution space. In other words, regardless of other existing members in population, mutation operators apply small changes over chromosome so as to increase the quality of obtained good solutions in the optimization process to a possible extent. In this mechanism, two mutation operators are applied: swap and reversion.

In this type of mutation, two columns of chromosome are first randomly selected and their values are interchanged. Figure 4 depicts a given sample of this type.

According to Figure 4, columns 4 and 8 are randomly selected and their positions are then swapped. For instance, in the initial chromosome, team \#4 presents service 1 to customer 1 and, then, goes to customer 2 to fulfill service 3 . The changes occurring through the mutation operator prompt team \#4 to go to customer 2 first to provide service 3 and then, visit customer 1 to accomplish service 1 . Similar changes happen to team \#2.

In this type of mutation, two columns of initial chromosome are first selected randomly and the columns between these selected columns are reversed from right to left. Figure 5 illustrates a given sample of this type.

According to Figure 5, columns 4 and 8 are selected as mutation points; columns 4 to 8 are reversed from right to left and the new offspring are then obtained.

\subsubsection{Stopping criterion}

Among different stopping criteria proposed in the literature, reaching a predetermined number of itera-

\begin{tabular}{|c|c|c|c|c|c|c|c|c|c|c|}
\hline \multicolumn{11}{|c|}{ Cut point } \\
\hline \multirow{2}{*}{ Parent 1} & $d_{1.2 .2}$ & $d_{1.1 .1}$ & $d_{2.3 .2}$ & $d_{1.2 .1}$ & $d_{3.1 .2}$ & $d_{1.1 .2}$ & $d_{3.1 .1}$ & $d_{1.3 .2}$ & $d_{2.1 .2}$ & $d_{3.2 .2}$ \\
\hline & 2 & 3 & 1 & 2 & 2 & 1 & 4 & 4 & 2 & 3 \\
\hline \multirow{2}{*}{ Parent 2} & $d_{1.2 .1}$ & $d_{1.2 .2}$ & $d_{2.3 .2}$ & $d_{1.1 .1}$ & $d_{2.1 .2}$ & $d_{3.1 .1}$ & $d_{1.3 .2}$ & $d_{1.1 .2}$ & $d_{3.2 .2}$ & $d_{3.1 .2}$ \\
\hline & 2 & 2 & 1 & 3 & 2 & 4 & 4 & 1 & 3 & 2 \\
\hline \multirow{2}{*}{ Child 1} & $d_{1.2 .2}$ & $d_{1.1 .1}$ & $d_{2.3 .2}$ & $d_{1.2 .1}$ & $d_{2.1 .2}$ & $d_{3.1 .1}$ & $d_{1.3 .2}$ & $d_{1.1 .2}$ & $d_{3.2 .2}$ & $d_{3.1 .2}$ \\
\hline & 2 & 3 & 1 & 2 & 2 & 4 & 4 & 1 & 3 & 2 \\
\hline \multirow{2}{*}{ Child 2} & $d_{1.2 .1}$ & $d_{1.2 .2}$ & $d_{2.3 .2}$ & $d_{1.1 .1}$ & $d_{3.1 .2}$ & $d_{1.1 .2}$ & $d_{3.1 .1}$ & $d_{1.3 .2}$ & $d_{2.1 .2}$ & $d_{3.2 .2}$ \\
\hline & 2 & 2 & 1 & 3 & 2 & 1 & 4 & 4 & 2 & 3 \\
\hline
\end{tabular}

Figure 3. Crossover operator.

\begin{tabular}{|c|c|c|c|c|c|c|c|c|c|c|}
\hline \multirow{2}{*}{ Parent } & $d_{1.2 .2}$ & $d_{1.1 .1}$ & $d_{2.3 .2}$ & $d_{1.2 .1}$ & $d_{3.1 .2}$ & $d_{1.1 .2}$ & $d_{3.1 .1}$ & $d_{1.3 .2}$ & $d_{2.1 .2}$ & $d_{3.2 .2}$ \\
\hline & 2 & 3 & 1 & 2 & 2 & 1 & 4 & 4 & 2 & 3 \\
\hline \multirow{2}{*}{ Child } & $d_{1.2 .2}$ & $d_{1.1 .1}$ & $d_{2.3 .2}$ & $d_{1.3 .2}$ & $d_{3.1 .2}$ & $d_{1.1 .2}$ & $d_{3.1 .1}$ & $d_{1.2 .1}$ & $d_{2.1 .2}$ & $d_{3.2 .2}$ \\
\hline & 2 & 3 & 1 & 4 & 2 & 1 & 4 & 2 & 2 & 3 \\
\hline
\end{tabular}

Figure 4. A given sample of swap mutation. 


\begin{tabular}{|c|c|c|c|c|c|c|c|c|c|c|}
\hline \multirow{2}{*}{ Parent } & $d_{1.2 .2}$ & $d_{1.1 .1}$ & $d_{2.3 .2}$ & $d_{1.2 .1}$ & $d_{3.1 .2}$ & $d_{1.1 .2}$ & $d_{3.1 .1}$ & $d_{1.3 .2}$ & $d_{2.1 .2}$ & $d_{3.2 .2}$ \\
\hline & 2 & 3 & 1 & 2 & 2 & 1 & 4 & 4 & 2 & 3 \\
\hline \multirow{2}{*}{ Child } & $d_{1.2 .2}$ & $d_{1.1 .1}$ & $d_{2.3 .2}$ & $d_{1.3 .2}$ & $d_{3.1 .1}$ & $d_{1.1 .2}$ & $d_{3.1 .2}$ & $d_{1.2 .1}$ & $d_{2.1 .2}$ & $d_{3.2 .2}$ \\
\hline & 2 & 3 & 1 & 4 & 4 & 1 & 2 & 2 & 2 & 3 \\
\hline
\end{tabular}

Figure 5. A given sample of reversion mutation.

tions/generations is set as the stopping criterion in the applied NSGA-II in this study.

\section{Analysis and evaluation of results}

In this section, the proposed model and solution approaches and also their applicability to solving reals problems are evaluated. To do so, maintenance scheduling of CNG stations equipment in Iran as a real case study in the defined UPMS_MFC area is investigated in this research. According to this case study, a small-sized sample is first defined and outputs of different solution approaches are then analyzed and evaluated. Next, some representations of this case in different sizes (number of CNG stations, number of repairs in different periods, number of factories and servicing teams, etc. change the problem size) are presented and the proposed solution approaches are evaluated and compared. The mathematical model is coded in GAMS 24.7.1 and solved by the CPLEX solver on a $\mathrm{PC}$ with a $2.5 \mathrm{GHz}$ Intel ${ }^{\circledR}$ Core $^{\mathrm{TM}}$ i5 processor and 6 GB RAM memory. Also, NSGA-II is coded in MATLAB 2016b.

\subsection{Case study}

As already mentioned, the investigated case in this research studies UPMS_MFC problem to yield the optimum maintenance scheduling of CNG stations equipment in Iran. These stations are usually located in different places, each of which has specific equipment (such as compressor, dispenser, dryer, etc.) supplied from different brands and companies, as depicted in Figure 6. Each of these equipment has a usual standard norm for control and repair. The supervisors of these stations offer existing fundamental equipment along with their brand and forecasted maintenance scheduling in each station to the general manager of all CNG stations.

National Iranian Oil Products Distribution Company (NIOPDC) is responsible for integrated management of all CNG stations in Iran. Moreover, implementation of optimum maintenance scheduling of CNG stations in charge of NIOPDC and its managers attempts to save expenditures and ensures minimum tardiness and earliness through running such an optimum schedule.

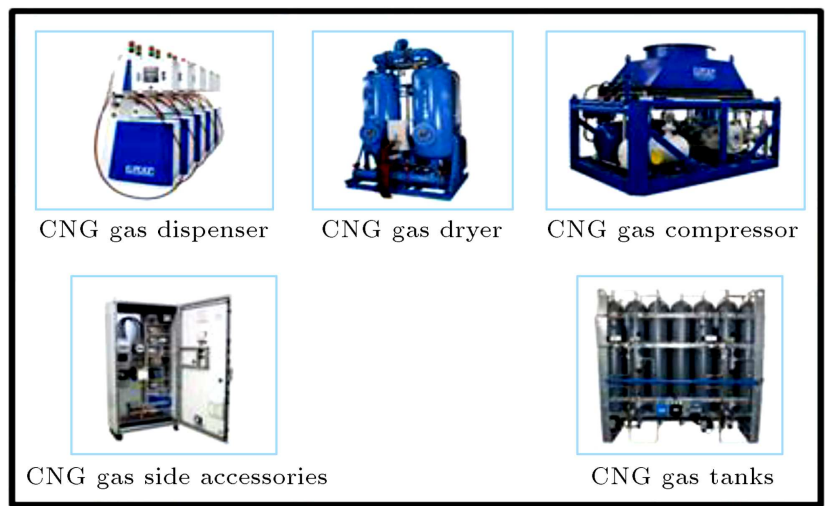

Figure 6. Some of existing fundamental equipment in a Compressed Natural Gas (CNG) station requiring periodic maintenance.

Existing equipment in each CNG station is purchased from different brands and companies located in in different places. Suppose that equipment E belongs to brand $\mathrm{B}$. If this equipment is maintained by instruments of brand B (its supplier), the minimum time and cost should be spent; otherwise, this repair should be carried out by other brands that incur a longer time and more costs.

In each factory, there are a finite number of teams to implement customers maintenance plan (CNG stations in this study), each of which fulfills specific maintenance (not necessarily, any type of maintenance). In addition to the provided information of CNG stations (forecasted maintenance scheduling), related statistics about establishment places of factories and their limitation on offering services along with maintenance expenditures are reported to managers of NIOPDC.

It is clear that NIOPDC could implement the maintenance scheduling without any tardiness or earliness and with minimum cost if the number of servicing teams in each factory is infinite with thorough availability to all regions. However, in practice, the limitation of servicing teams on the one side and dispersion of $\mathrm{CNG}$ stations on the other side (may cause inaccessibility to some factories due to long distance) result in much complexity in running this schedule, and making a decision about it will be difficult. This obstacle becomes more unintelligible when the maintenance schedule should cover the larger number of stations, 


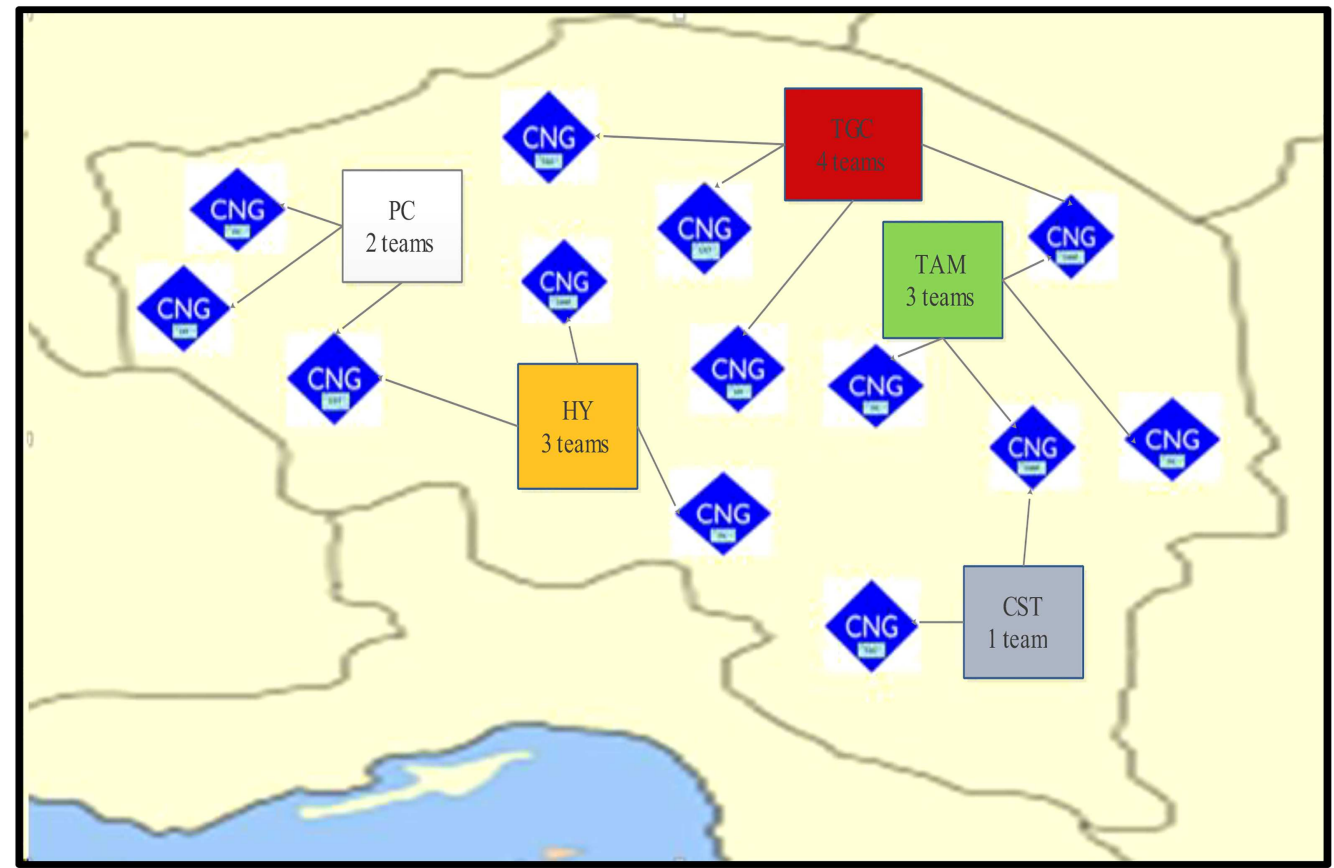

Figure 7. A representation of providing maintenance services network from factories to Compressed Natural Gas (CNG) stations.

Table 2. Maintenance scheduling of Compressed Natural Gas (CNG) stations (annually).

\begin{tabular}{cccccc}
\hline CNG stations & \multicolumn{5}{c}{ Equipment and maintenance periods } \\
\cline { 2 - 6 } & Compressor & Dryer & Dispenser & Tanks & Others \\
\hline CNG1 & $9-5-1$ & $6-1$ & $9-5-1$ & 6 & $9-3$ \\
CNG2 & $9-6-2$ & $6-1$ & $9-6-2$ & 6 & $9-3$ \\
CNG3 & $9-5-1$ & $6-1$ & $9-5-1$ & 6 & $9-3$ \\
CNG4 & $9-5-1$ & $6-1$ & $9-5-1$ & $7-1$ & $9-3$ \\
CNG5 & $10-6-2$ & $8-2$ & $10-6-2$ & 6 & $7-1$ \\
CNG6 & $9-5-2$ & $8-2$ & $9-5-2$ & 6 & $7-1$ \\
CNG7 & $10-5-1$ & $6-1$ & $10-5-1$ & 6 & $9-3$ \\
CNG8 & $10-5-1$ & $8-2$ & $10-5-1$ & $7-1$ & $9-3$ \\
CNG9 & $10-5-1$ & $6-1$ & $10-5-1$ & 6 & $9-3$ \\
CNG10 & $10-5-1$ & $6-1$ & $10-5-1$ & 6 & $9-3$ \\
CNG11 & $10-5-1$ & $6-1$ & $10-5-1$ & 6 & $9-3$ \\
CNG12 & $10-5-1$ & $6-1$ & $10-5-1$ & 6 & $9-3$ \\
CNG13 & $10-6-2$ & $8-2$ & $10-6-2$ & 6 & $7-1$ \\
\hline
\end{tabular}

more types of repairs, and larger number of factories and servicing teams. The investigated case study is a sample of the defined UPMS_MFC problem in this research which could be solved using the proposed model and solution approaches, where the results can significantly help the managers of NIOPDC to make the best decisions.

\subsection{Validation of the proposed solution approaches}

In this subsection, a representation of explored case study in small size (with 13 stations, 5 factories with 13 servicing teams, and 5 types of service correspondent to those equipment pieces in Figure 6) is presented in Figure 7, in which the initial evaluation of the proposed solution approaches is carried out using this small sample. Table 2 shows maintenance scheduling of CNG stations (annually) and it can be observed that each station needs what maintenance in which periods.

\subsubsection{Evaluation of $A E C$ method compared to NSGA-II}

In order to obtain the optimal/global Pareto front, the proposed mathematical model and AEC exact method are first employed for solving the studied bi-objective problem in small sizes. The NSGA-II method is then 
employed for the same reason and its obtained Pareto front is compared with the Pareto front gained from hybrid method LexAEC (hybridization of AEC and Lex method). The first objective function is determined with 'Cost', while the second one is specified with Time Window Unsatisfaction (TWU) in Tables 3 and 4. Figure 8 and Figure 9 show the Pareto fronts of AEC method and NSGA-II, respectively, and they are compared with those in Figure 10.

In order to compare the results of AEC exact method and NSGA-II, a small instance of UPMS_MFC problem is solved. The obtained Pareto fronts of both algorithms are depicted in Figure 10, simultaneously.

Table 3. Trade-off between cost and customers' unsatisfaction using Augmented Epsilon Constraint (AEC) method.

\begin{tabular}{ccc}
\hline $\begin{array}{c}\text { Pareto } \\
\text { solution }\end{array}$ & $\begin{array}{c}\text { First objective } \\
\text { function's value } \\
\text { (Cost) }\end{array}$ & $\begin{array}{c}\text { Second objective } \\
\text { function's value } \\
\text { (TWU) }\end{array}$ \\
\hline 1 & 7127 & 0 \\
2 & 6513 & 20 \\
3 & 6110 & 20 \\
4 & 5510 & 30 \\
5 & 5178 & 40 \\
6 & 4650 & 60 \\
7 & 4045 & 130 \\
8 & 3750 & 190 \\
9 & 3625 & 230 \\
10 & 3310 & 280 \\
11 & 3150 & 340 \\
12 & 3098 & 370 \\
\hline
\end{tabular}

Table 4. Trade-off between cost and customers' unsatisfaction using NSGA-II method.

\begin{tabular}{ccc}
\hline $\begin{array}{c}\text { Pareto } \\
\text { solution }\end{array}$ & $\begin{array}{c}\text { First objective } \\
\text { function's value } \\
\text { (Cost) }\end{array}$ & $\begin{array}{c}\text { Second objective } \\
\text { function's value } \\
\text { (TWU) }\end{array}$ \\
\hline 1 & 7349 & 0 \\
2 & 6513 & 20 \\
3 & 5890 & 30 \\
4 & 5178 & 40 \\
5 & 4850 & 50 \\
6 & 4245 & 140 \\
7 & 3690 & 180 \\
8 & 3625 & 230 \\
9 & 3512 & 280 \\
10 & 3150 & 340 \\
11 & 3098 & 370 \\
12 & 7349 & 0 \\
\hline
\end{tabular}

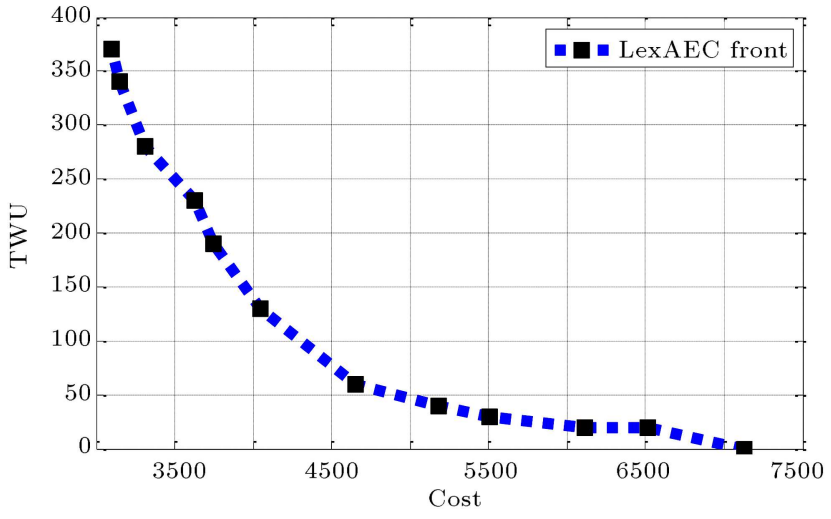

Figure 8. Pareto front obtained by Augmented Epsilon Constraint (AEC) method.

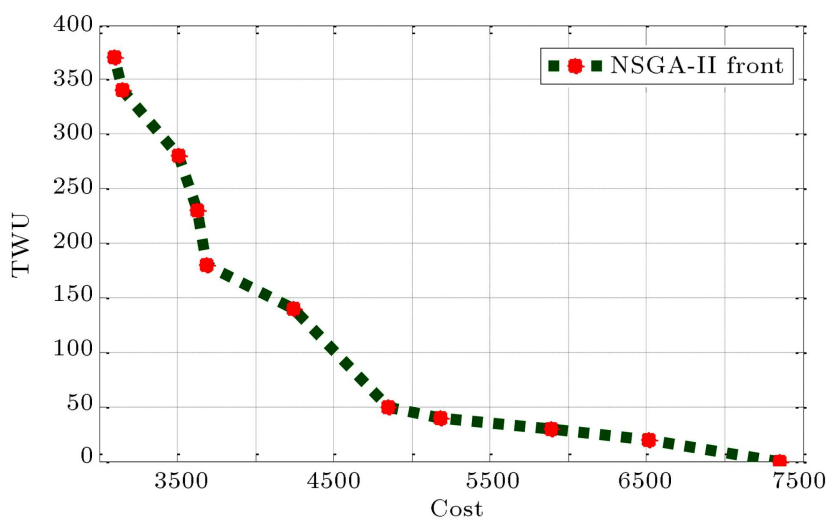

Figure 9. Pareto front obtained by NSGA-II method.

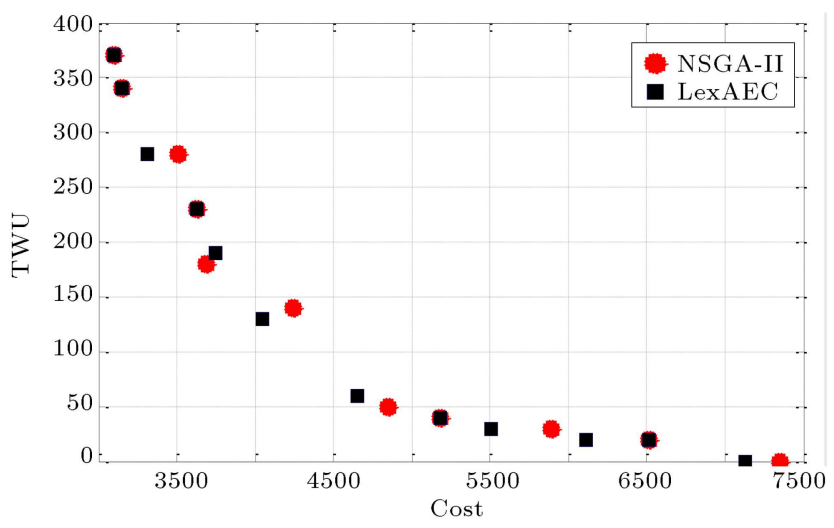

Figure 10. Comparison of Pareto fronts obtained by Augmented Epsilon Constraint (AEC) and NSGA-II methods.

Since this problem is small sized, it was already also anticipated that the AEC method could outperform NSGA-II; however, NSGA-II has acceptable performance in this sample instance, where its Pareto front is close to global front gained by AEC method to a large extent. In practice, a solution should be opted from Pareto optimal front by managers/decisionmakers through doing a trade-off between solutions. In Figure 11, a given space is suggested to select the 


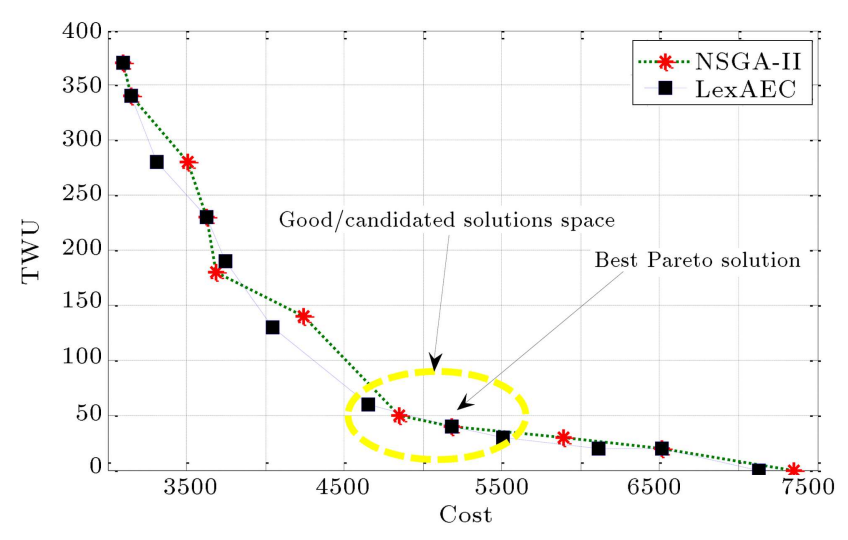

Figure 11. Suggested area to select Pareto solutions.

Pareto front among different obtained solutions, since the rate of incremental costs is more than the rate of reduction costs to a large extent.

In order to compare the results of $\mathrm{AEC}$ exact method and NSGA-II, a small instance of UPMS_MFC problem is solved. The obtained Pareto fronts of both algorithms are depicted in Figure 10, simultaneously. Since this problem is small sized, it was already also anticipated that the AEC method can outperform NSGA-II; however, NSGA-II has acceptable performance in this sample instance, where its Pareto front is close to the global front gained by AEC method to a large extent. In practice, a solution should be opted from Pareto optimal front by managers/decisionmakers through a trade-off between solutions. In Figure 11, a given space is suggested to select the Pareto front among different obtained solutions, since the rate of incremental costs is more than that of reduction costs to a large extent.

\subsubsection{Evaluation of RPP approach to control uncertainty}

In this subsection, RPP approach to controlling UPMS_MFC uncertainty defined in this research is assessed. The two criteria "deviation from optimality" and "constraints violation" are derived from the most important indices for evaluating the performance of optimization approaches in uncertain conditions. To use these criteria, the uncertain parameter in this study, i.e., processing times (duration time of maintenance in case study), is simulated 20 times and the performance of the proposed RPP approach is evaluated.

It is assumed that the average of fuzzy data $\left(\frac{P_{j i f}^{1}+2 P_{j i f}^{2}+2 P_{j i f}^{3}+P_{j i f}^{4}}{6}\right)$ in the nominal value approach is replaced with them. In the robust possibilistic (Robust I) approach, this value has already been determined similar to possibility measure $\alpha(\alpha=95 \%$ is considered in this research). Finally, in RPP approach (Robust II), $\alpha$ is considered a variable obtained by solving the model. According to the obtained results in Figures 12 and 13, it can be observed that optimality

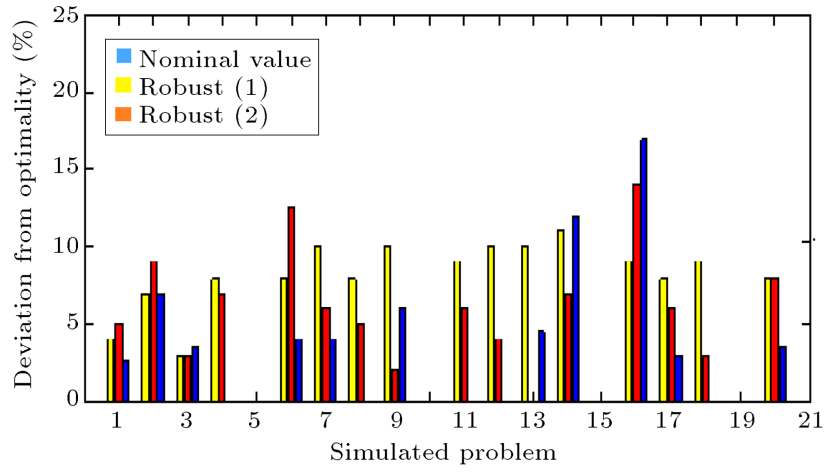

Figure 12. "Deviation from optimality" criterion in comparison to robust and nominal approaches.

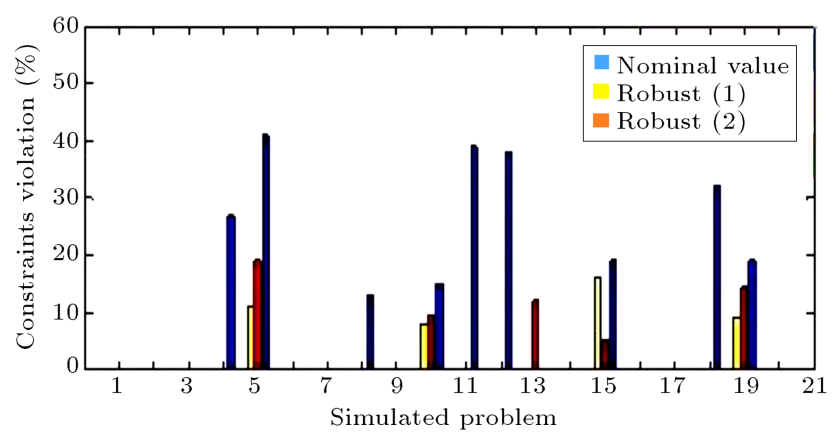

Figure 13. "Constraints violation" criterion in comparison to robust and nominal approaches.

fluctuations in the proposed robust approaches are quite lower than those in the nominal value approach. Second, the proposed robust possibilistic approaches significantly reduce violations of constraints than the nominal value approach, which itself diminishes the risk of decision-making.

\subsection{Evaluation of solution approaches to large-sized problems}

In Subsection 5.2.1, a representation of UPMS_MFC problem was solved in small sizes, where according to its results, it could be observed that the Pareto fronts obtained from NSGA-II were to a large extent close to global optimal Pareto fronts, illustrating its acceptable performance. In this subsection, validation of the proposed meta-heuristic algorithm, NSGA-II, is evaluated in a more comprehensive space for large-size instances. To do so, some measures are first defined and some experimental instances in different sizes are then designed. Results of AEC exact method and NSGA-II as a meta-heuristic algorithm are compared, as shown in Tables $5-8$.

\subsubsection{Cover Set (CS)}

In this criterion, the number of non-dominated solutions in each method is compared with those in other methods [51]. Consider two solution approaches $A$ and $B$ for a given MODM problem, where $F(A)$ and $F(B)$ signify the Pareto fronts obtained from the solution 
Table 5. Scale of Unrelated Parallel Machine Scheduling with Multiple Factories/servers and Clients (UPMS_MFC) test problems (small-scaled).

\begin{tabular}{cccccc}
\hline $\begin{array}{c}\text { No. of } \\
\text { instance }\end{array}$ & $\begin{array}{c}\text { Planning } \\
\text { periods }\end{array}$ & $\begin{array}{c}\text { Maintenance/ } \\
\text { job }\end{array}$ & $\begin{array}{c}\text { Locations/ } \\
\text { CNG stations }\end{array}$ & Teams & Factory \\
\hline 1 & 4 & 2 & 5 & 2 & 2 \\
2 & 4 & 2 & 6 & 2 & 2 \\
3 & 4 & 2 & 7 & 3 & 3 \\
4 & 4 & 3 & 8 & 4 & 3 \\
5 & 6 & 3 & 10 & 5 & 3 \\
6 & 6 & 4 & 10 & 5 & 4 \\
7 & 6 & 4 & 12 & 5 & 4 \\
8 & 6 & 5 & 14 & 6 & 4 \\
9 & 6 & 5 & 15 & 7 & 5 \\
10 & 6 & 6 & 20 & 7 & 5 \\
\hline
\end{tabular}

Table 6. Scale of Unrelated Parallel Machine Scheduling with Multiple Factories/servers and Clients (UPMS_MFC) test problems (large-scale).

\begin{tabular}{|c|c|c|c|c|c|}
\hline $\begin{array}{l}\text { No. of } \\
\text { instance }\end{array}$ & $\begin{array}{l}\text { Planning } \\
\text { periods }\end{array}$ & $\begin{array}{c}\text { Maintenance/ } \\
\text { job }\end{array}$ & $\begin{array}{c}\text { Locations / } \\
\text { CNG stations }\end{array}$ & Teams & Factory \\
\hline 1 & 6 & 5 & 30 & 10 & 10 \\
\hline 2 & 6 & 6 & 30 & 12 & 10 \\
\hline 3 & 6 & 7 & 30 & 12 & 15 \\
\hline 4 & 12 & 8 & 30 & 12 & 15 \\
\hline 5 & 12 & 9 & 35 & 13 & 20 \\
\hline 6 & 12 & 10 & 40 & 14 & 20 \\
\hline 7 & 12 & 10 & 45 & 15 & 20 \\
\hline 8 & 12 & 10 & 50 & 16 & 20 \\
\hline 9 & 12 & 11 & 60 & 20 & 20 \\
\hline 10 & 12 & 12 & 70 & 22 & 20 \\
\hline
\end{tabular}

Table 7. Comparison of the proposed solution approaches according to evaluation measures (small-scaled).

\begin{tabular}{clccccc}
\hline Instance & $\begin{array}{c}\text { CS } \\
\text { (AEC, NSGA-II) }\end{array}$ & $\begin{array}{c}\text { MID } \\
\text { (AEC) }\end{array}$ & $\begin{array}{c}\text { MID } \\
\text { (NSGA-II) }\end{array}$ & $\begin{array}{c}\text { NOS } \\
\text { (AEC) }\end{array}$ & $\begin{array}{c}\text { NOS } \\
\text { (NSGA-II) }\end{array}$ & $\begin{array}{c}\text { NS_CS } \\
\text { (AEC, NSGA-II) }\end{array}$ \\
\hline 1 & 0 & 150.83 & 150.83 & 4 & 4 & 4 \\
2 & 0 & 134.60 & 134.60 & 4 & 4 & 4 \\
3 & 0.33 & 221.89 & 203.12 & 5 & 6 & 4 \\
4 & 0 & 304.05 & 287.24 & 7 & 8 & 8 \\
5 & 0.20 & 287.51 & 275.31 & 11 & 10 & 13 \\
6 & 0 & 351.43 & 390.64 & 13 & 13 & 12 \\
7 & 0.14 & 400.85 & 430.65 & 16 & 14 & 14 \\
8 & 0.07 & 531.15 & 494.65 & 17 & 15 & 15 \\
9 & 0 & 560.13 & 559.08 & 17 & 15 & 17 \\
10 & 0 & 587.42 & 604.15 & 19 & 17 & \\
\hline
\end{tabular}

approaches $A$ and $B$, respectively. Also, for each member, $p a \in F(A)$ and $p b \in F(B)$, and the symbol pa Dom $p b$ indicates the dominance of $p a$ over $p b$ (or, equivalently, dominance of $p b$ over $p a$ ).

According to these definitions, the measure CS is introduced so as to compare the two solution approaches $A$ and $B$ as follows:

$$
C S(A, B)=\frac{\{p b \in F(B) \mid \exists p a \in F(A): p a \text { Dom } p b\}}{F(B)} .
$$

As a matter of fact, the measure $C S(A, B)$ shows the portion of total Pareto solutions of method $B$ which are dominated by at least one of the Pareto solutions of method $A$. It is obvious that $0 \leq C S(A, B) \leq 1$. 
Table 8. Performance of the proposed NSGA-II and its stability in large-scale instances.

\begin{tabular}{|c|c|c|c|c|c|c|c|c|c|c|c|c|}
\hline \multirow[b]{2}{*}{ Instance } & \multicolumn{4}{|c|}{ MID } & \multicolumn{4}{|c|}{ NOS } & \multicolumn{4}{|c|}{ Run time ( $\min )$} \\
\hline & $\mathbf{M}$ & B & $\mathbf{W}$ & $\mathrm{SD} / \mathrm{M}$ & $\mathbf{M}$ & $\mathbf{B}$ & $\mathbf{W}$ & $\mathrm{SD} / \mathrm{M}$ & M & $\mathbf{B}$ & $\mathbf{W}$ & SD \\
\hline 1 & 820.65 & 812.23 & 903.21 & 0.037 & 25 & 28 & 24 & 0.053 & 20.56 & 18.21 & 21.32 & 0.050 \\
\hline 2 & 928.76 & 873.3 & 980.43 & 0.038 & 31 & 33 & 29 & 0.043 & 26.87 & 24.32 & 28.04 & 0.046 \\
\hline 3 & 1070.67 & 1008.37 & 1090.43 & 0.026 & 28 & 28 & 28 & 0.000 & 33.9 & 31.46 & 34.12 & 0.026 \\
\hline 4 & 1324.59 & 1279.49 & 1333.56 & 0.014 & 30 & 32 & 27 & 0.056 & 41.41 & 39.95 & 44.12 & 0.034 \\
\hline 5 & 1351.73 & 1343.73 & 1411.73 & 0.017 & 35 & 37 & 33 & 0.038 & 53.43 & 51.75 & 57.84 & 0.038 \\
\hline 6 & 1377.90 & 1289.43 & 1448.65 & 0.039 & 37 & 40 & 36 & 0.036 & 70.12 & 65.42 & 73.65 & 0.039 \\
\hline 7 & 1630.59 & 1572.43 & 1697.65 & 0.026 & 40 & 40 & 38 & 0.017 & 90.31 & 86.43 & 95.31 & 0.033 \\
\hline 8 & 1635.80 & 1578.21 & 1728.54 & 0.031 & 42 & 45 & 41 & 0.032 & 120.86 & 116.23 & 127.64 & 0.031 \\
\hline 9 & 1746.24 & 1665.24 & 1766.51 & 0.019 & 38 & 41 & 37 & 0.035 & 150.43 & 141.42 & 153.74 & 0.027 \\
\hline 10 & 1875.79 & 1868.73 & 1933.53 & 0.037 & 41 & 43 & 41 & 0.053 & 196.98 & 183.43 & 202.09 & 0.050 \\
\hline
\end{tabular}

Abbreviations: M: Mean; B: Best; W: Worst; SD/M: Standard Deviation per Mean

- If $C S(A, B)$ is close to 0 , then method $B$ has better performance than $A$ and most of the solutions are efficient;

- If $C S(A, B)$ is close to 1 , then method $A$ has better performance than $B$ and most of the solutions are efficient;

- The lower the value of $C S(A, B)$, the better the performance of method $B$.

\subsubsection{Mean of Ideal Distance (MID)}

In this criterion, as one of the most important criteria for measurement of MODM problems [34], an ideal solution is first considered for the on-hand problem and mean deviations of Pareto solutions from ideal solutions are then calculated. The ideal solution shown by $I_{\text {sol }}$ is called to an status in which both solutions are simultaneously optimum, i.e., $I_{\text {sol }}=$ $\left(\min \left(Z_{1}\right), \min \left(Z_{2}\right)\right)$. It is obvious that in problems in which all of objective functions are "minimization", one can set the origin of the coordinate as the ideal solutions, i.e., $I_{s o l}=(0,0)$.

If $F(A)$ signifies the Pareto front obtained from the solution approach $A$, MID criterion is calculated as follows:

$$
\operatorname{MID}(A)=\frac{\sum_{p a \in F(A)} p a-I_{s o l 2}}{F(A)},
$$

where $I_{\text {sol }}-p a_{2}$ shows the Euclidean distance of solutions pa $\in F(A)$ from ideal solutions. Clearly, the lower the value of MID criterion, the better its performance.

\subsubsection{Number Of Solutions (NOS) or solutions quantity}

In this criterion, the number of obtained Pareto solutions is computed. The method with a larger NOS performs better. For method $A$, this criterion acts as
$\operatorname{NOS}(A)=F(A)$. Despite the usefulness of NOS in measuring the diversity of solutions, it has a major weakness, that is, the quality of solutions cannot be clearly observed. This obstacle is overcome in the next measure.

\subsubsection{Number of non-dominated solutions (NS_CS) or solutions quality}

One of the weaknesses of NOS is when $\operatorname{NOS}(B)>$ $\operatorname{NOS}(A)$, while $C S(A, B)$ is a large number. This means that most of the obtained solutions by method $B$ are dominated by those gained from method $A$. However, according to NOS, as it can be seen, method $B$ outperforms method $A$. To fix this difficulty, a hybrid criterion called NS_CS is introduced as follows:

$$
N S \_C S(A, B)=[N O S(B) .(1-C S(A, B))] .
$$

In fact, $N S_{-} C S(A, B)$ counts the number of the Pareto solutions obtained from method B which are not dominated by solutions of method $A$. It is evident that the higher the value of $N S \_C S(A, B)$, the better the performance of method $B$.

\section{Conclusions and future studies}

This study investigated the scheduling of periodic services from heterogeneous multi-agent companies to customers located in dispersed locations with different needs and services. For this problem called Unrelated Parallel Machine Scheduling with Multiple Factories/servers and Client (UPMS_MFC), two objective functions were considered: service costs and tardiness/earliness minimization. To solve this problem, first, a bi-objective Mixed Integer Linear Programming (MILP) model handled by Augmented Epsilon Constraint (AEC) was developed and then, a metaheuristic method called NSGA-II was proposed. In addition, to handle the uncertainty of some parameters, 
the Robust Possibilistic Programming (RPP) approach was employed.

To evaluate the performance of the proposed biobjective MILP and NSGA-II solution methods, several experimental problems were randomly generated and different criteria such as Mean of Ideal Distance (MID), Number Of Solution (NOS), and NS_CS were used. The obtained results showed that the global Pareto fronts could be obtained for small-sized instances using the proposed AEC exact method. Also, NSGA-II had a comparable performance against AEC in small-sized instances, which is acceptable. This can ensure that one employs NSGA-II to solve large-sized problems for which AEC is not capable to solve the problems. Furthermore, to show the stability of the proposed meta-heuristics method in solving large-scale test problems, the NSGA-II method was implemented several times for each experimental problem. According to the results, the performance was acceptable and the proposed NSGA-II approach was reliable for solving various large-scale problems.

Using simulated numerical instances, it could be observed that 'constraints violation' and 'deviation from optimality', as two important indices of the optimization approaches performance in uncertain conditions, significantly decreased in the RPP approach, which in turn, diminished the risk of decision-making.

As a stream for future studies, one can consider the impact of maintenance scheduling on the reliability of equipment in a company, wherein the probability of activity interference for each facility is lower than a predetermined bound. Another interesting direction can be to take the uncertainty of the other parameters into account and present different powerful metaheuristic algorithms to tackle the studied problem.

\section{References}

1. Behnamian, J. and Ghomi, S.F. "The heterogeneous multi-factory production network scheduling with adaptive communication policy and parallel machine", Information Sciences, 219, pp. 181-196 (2013).

2. Wu, T.-H., Chang, C.-C., and Chung, S.-H. "A simulated annealing algorithm for manufacturing cell formation problems", Expert Systems with Applications, 34(3), pp. 1609-1617 (2008).

3. Niwas, R. and Garg, H. "An approach for analyzing the reliability and profit of an industrial system based on the cost free warranty policy", Journal of the Brazilian Society of Mechanical Sciences and Engineering, 40(5), p. 265 (2018).

4. Wu, S.-J., Gebraeel, N., Lawley, M.A., and Yih, Y. "A neural network integrated decision support system for condition-based optimal predictive maintenance policy", IEEE Transactions on Systems, Man, and Cybernetics-Part A: Systems and Humans, 37(2), pp. 226-236 (2007).
5. Vasili, M., Hong, T.S., Ismail, N., and Vasili, M. "Maintenance optimization models: a review and analysis", In Proceedings of the 2011 International Conference on Industrial Engineering and Operations Management, Kuala Lumpur, Malaysia, January 2224, pp. 1131-1138 (2011).

6. Al-Najjar, B. "The lack of maintenance and not maintenance which costs: A model to describe and quantify the impact of vibration-based maintenance on company's business", International Journal of Production Economics, 107(1), pp. 260-273 (2007).

7. Al-Najjar, B. and Alsyouf, I. "Enhancing a company's profitability and competitiveness using integrated vibration-based maintenance: A case study", European Journal of Operational Research, 157(3), pp. 643-657 (2004).

8. Kathleen, E.M. and Elliott, N.W. "Total productive maintenance (TPM)", Encyclopedia of Production and Manufacturing Management, pp. 796-803 (2000).

9. Vineyard, M., Amoako-Gyampah, K., and Meredith, J.R. "An evaluation of maintenance policies for flexible manufacturing systems: a case study", International Journal of Operations \& Production Management, 20(4), pp. 409-426 (2000).

10. Chung, S., Lau, H.C., Choy, K., Ho, G.T., and Tse, Y. "Application of genetic approach for advanced planning in multi-factory environment", International Journal of Production Economics, 127(2), pp. 300-308 (2010).

11. Doostparast, M., Kolahan, F., and Doostparast, M. "Optimisation of PM scheduling for multi-component systems-a simulated annealing approach", International Journal of Systems Science, 46(7), pp. 11991207 (2015).

12. Ebrahimipour, V., Najjarbashi, A., and Sheikhalishahi, M. "Multi-objective modeling for preventive maintenance scheduling in a multiple production line", Journal of Intelligent Manufacturing, 26(1), pp. 111122 (2015).

13. Ovacik, I.M. and Uzsoy, R., Decomposition Methods for Complex Factory Scheduling Problems, Springer Science \& Business Media (2012).

14. Lee, H. "Heuristic for scheduling on nonidentical machines to minimize tardy jobs", International Journal of Industrial Engineering: Theory Applications and Practice, 7(3), pp. 188-194 (2000).

15. Balakrishnan, N., Kanet, J.J., and Sridharan, V. "Early/tardy scheduling with sequence dependent setups on uniform parallel machines", Computers \& Operations Research, 26(2), pp. 127-141 (1999).

16. Zhu, Z. and Heady, R.B. "Minimizing the sum of earliness/tardiness in multi-machine scheduling: a mixed integer programming approach", Computers \& Industrial Engineering, 38(2), pp. 297-305 (2000).

17. Rocha, P.L., Ravetti, M.G., Mateus, G.R., and Pardalos, P.M. "Exact algorithms for a scheduling problem with unrelated parallel machines and sequence and 
machine-dependent setup times", Computers \& Operations Research, 35(4), pp. 1250-1264 (2008).

18. Ruiz, R., Andrés, C., Baptiste, P., Kendall, G., Munier-Kordon, A., and Sourd, F. "Unrelated parallel machines scheduling with resource-assignable sequence dependent setup times", in Proceedings of the 3rd Multidisciplinary International Conference on Scheduling, Theory and Applications (MISTA) (2007).

19. Kanyalkar, A. and Adil*, G. "An integrated aggregate and detailed planning in a multi-site production environment using linear programming", International Journal of Production Research, 43(20), pp. 4431-4454 (2005).

20. Kerkhove, L.-P. and Vanhoucke, M. "Scheduling of unrelated parallel machines with limited server availability on multiple production locations: a case study in knitted fabrics", International Journal of Production Research, 52(9), pp. 2630-2653 (2014).

21. Behnamian, J. and Fatemi Ghomi, S.M.T. "A survey of multi-factory scheduling", Journal of Intelligent Manufacturing, 27(1), pp. 231-249 (2016).

22. Woo, Y.-B., Jung, S., and Kim, B.S. "A rule-based genetic algorithm with an improvement heuristic for unrelated parallel machine scheduling problem with timedependent deterioration and multiple rate-modifying activities", Computers \& Industrial Engineering, 109, pp. 179-190 (2017).

23. Mensendiek, A., Gupta, J.N., and Herrmann, J. "Scheduling identical parallel machines with fixed delivery dates to minimize total tardiness", European Journal of Operational Research, 243(2), pp. 514-522 (2015).

24. Poursabzi, O., Mohammadi, M., and Naderi, B. "An improved model and a heuristic for capacitated lot sizing and scheduling in job shop problems", Scientia Iranica, 25(6), pp. 3667-3684 (2018).

25. Asadi-Gangraj, E. "Lagrangian relaxation approach to minimizing makespan in hybrid flow shop scheduling problem with unrelated parallel machines", Scientia Iranica, 25(6), pp. 3765-3775 (2018).

26. Dieter, A., Pickard, K., and Bertsche, B. "Periodic renewal of spare parts using Weibull", Quality and Reliability Engineering International, 26(3), pp. 193198 (2010).

27. Garg, H., Rani, M., and Sharma, S. "Preventive maintenance scheduling of the pulping unit in a paper plant", Japan Journal of Industrial and Applied Mathematics, 30(2), pp. 397-414 (2013).

28. Garg, H. and Sharma, S.P. "A two-phase approach for reliability and maintainability analysis of an industrial system", International Journal of Reliability, Quality and Safety Engineering, 19(03), p. 1250013 (2012).
29. Hosseini, S., Kalam, S., Barker, K., and RamirezMarquez, J.E. "Scheduling multi-component maintenance with a greedy heuristic local search algorithm", Soft Comput, 24(1), pp. 351-366 (2020).

30. Ji, M., He, Y., and Cheng, T.E. "Single-machine scheduling with periodic maintenance to minimize makespan", Computers \& Operations Research, 34(6), pp. 1764-1770 (2007).

31. Simeu-Abazi, Z. and Ahmad, A.A. "Optimisation of distributed maintenance: Modelling and application to the multi-factory production", Reliability Engineering \& System Safety, 96(11), pp. 1564-1575 (2011).

32. Xu, D., Sun, K., and Li, H. "Parallel machine scheduling with almost periodic maintenance and nonpreemptive jobs to minimize makespan", Computers \& Operations Research, 35(4), pp. 1344-1349 (2008).

33. Tavakkoli-Moghaddam, R., Taheri, F., Bazzazi, M., Izadi, M., and Sassani, F. "Design of a genetic algorithm for bi-objective unrelated parallel machines scheduling with sequence-dependent setup times and precedence constraints", Computers \& Operations Research, 36(12), pp. 3224-3230 (2009).

34. Volkanovski, A., Mavko, B., Bosevski, T., Causevski, A., and Cepin, M. "Genetic algorithm optimisation of the maintenance scheduling of generating units in a power system", Reliability Engineering \& System Safety, 93(6), pp. 779-789 (2008).

35. Kadri, R.L. and Boctor, F.F. "An efficient genetic algorithm to solve the resource-constrained project scheduling problem with transfer times: The single mode case", European Journal of Operational Research, 265(2), pp. 454-462 (2018).

36. Hosseinabadi, A.A.R., Vahidi, J., Saemi, B., Sangaiah, A.K., and Elhoseny, M. "Extended genetic algorithm for solving open-shop scheduling problem", Soft Computing, 23(13), pp. 5099-5116 (2019).

37. Garg, H. "A hybrid GSA-GA algorithm for constrained optimization problems", Information Sciences, 478, pp. 499-523 (2019).

38. Su, C. and Liu, Y. "Multi-objective imperfect preventive maintenance optimisation with NSGA-II", International Journal of Production Research, 58(13), pp. 4033-4049 (2020).

39. May, G., Stahl, B., Taisch, M., and Prabhu, V. "Multiobjective genetic algorithm for energy-efficient job shop scheduling", International Journal of Production Research, 53(23), pp. 7071-7089 (2015).

40. Dai, C., Cai, Y., Ren, W., Xie, Y., and Guo, H. "Identification of optimal placements of best management practices through an interval-fuzzy possibilistic programming model", Agricultural Water Management, 165, pp. 108-121 (2016).

41. Wan, S.-P. and Dong, J.-Y. "Possibility linear programming with trapezoidal fuzzy numbers", $A p$ plied Mathematical Modelling, 38(5-6), pp. 1660-1672 (2014). 
42. Tanaka, H., Okuda, T., and Asai, K. "Fuzzy mathematical programming", Transactions of the Society of Instrument and Control Engineers, 9(5), pp. 607-613 (1973).

43. Pishvaee, M.S., Razmi, J., and Torabi, S.A. "Robust possibilistic programming for socially responsible supply chain network design: A new approach", Fuzzy sets and systems, 206, pp. 1-20 (2012).

44. Ehrgott, M., Multicriteria Optimization, Springer Science \& Business Media (2005).

45. Marler, R.T. and Arora, J.S. "Survey of multiobjective optimization methods for engineering", Structural and Multidisciplinary Optimization, 26(6), pp. 369-395 (2004).

46. Mavrotas, G. "Effective implementation of the $\varepsilon$ constraint method in multi-objective mathematical programming problems", Applied Mathematics and Computation, 213(2), pp. 455-465 (2009).

47. Aghaei, J., Amjady, N., and Shayanfar, H.A. "Multiobjective electricity market clearing considering dynamic security by lexicographic optimization and augmented epsilon constraint method", Applied Soft Computing, 11(4), pp. 3846-3858 (2011).

48. Avalos-Rosales, O., Angel-Bello, F., and Alvarez, A. "Efficient metaheuristic algorithm and re-formulations for the unrelated parallel machine scheduling problem with sequence and machine-dependent setup times", The International Journal of Advanced Manufacturing Technology, 76(9-12), pp. 1705-1718 (2015).

49. Joo, C.M. and Kim, B.S. "Hybrid genetic algorithms with dispatching rules for unrelated parallel machine scheduling with setup time and production availability", Computers \& Industrial Engineering, 85, pp. 102-109 (2015).

50. Kim, D.-W., Kim, K.-H., Jang, W., and Frank Chen, F. "Unrelated parallel machine scheduling with setup times using simulated annealing", Robotics and Computer-Integrated Manufacturing, 18(3), pp. 223231 (2002).

51. Vallada, E. and Ruiz, R. "A genetic algorithm for the unrelated parallel machine scheduling problem with sequence dependent setup times", European Journal of Operational Research, 211(3), pp. 612-622 (2011).

\section{Biographies}

Hamed Jafar-Zanjani is currently a $\mathrm{PhD}$ candidate in Industrial Engineering with specialty in Automation at Science and Research Branch, Islamic Azad University, Tehran, Iran. He received his BSc degree in Industrial Engineering from Naragh Branch, Islamic Azad University, Markazi, Iran in 2003. He received his MSc degree in Industrial Engineering from Najaf Abad Branch, Islamic Azad University, Isfahan, Iran in 2006. He has more than thirteen years of experience in planning and project control in industrial engineering. His current research interests are scheduling and optimization techniques.

Mostafa Zandieh received his BSc degree in Industrial Engineering from Amirkabir University of Technology, Tehran, Iran in 1998 and MSc degree in Industrial Engineering from Sharif University of Technology, Tehran, Iran in 2000. He also obtained his PhD degree in Industrial Engineering from Amirkabir University of Technology, Tehran, Iran in 2006. Currently, he is a Professor at Industrial Management and Information Technology Department at Shahid Beheshti University, Tehran, Iran. His research interests are production planning and scheduling, financial engineering, quality engineering, applied operations research, simulation, and artificial intelligence techniques in the areas of manufacturing systems design.

Mohammad Khalilzadeh received his MSc and PhD degrees in Industrial Engineering from Sharif University of Technology, Tehran, Iran. He is currently an Assistant Professor at the Industrial Engineering Department of the Science and Research Branch of the Islamic Azad University, Tehran, Iran. His research interests are project management, fuzzy multiple-criteria decision making, and system thinking. 